\title{
Effects of virtual learning environments: A scoping review of literature
}

\author{
Laura Caprara $^{1} \cdot$ Cataldo Caprara $^{1}$
}

Received: 5 July 2021 / Accepted: 29 September 2021 / Published online: 6 October 2021

(C) The Author(s) 2021

\begin{abstract}
The purpose of this scoping review is to isolate and investigate the existing data and research that identifies if the synchronous face-to-face visual presence of a teacher in a virtual learning environment (VLE) is a significant factor in a student's ability to maintain good mental health. While the present research on this explicit interaction among VLE implementation and student mental health is limited, the material suggests a framework for strong utilization of VLEs. Overall, our research has shown that authentic, high quality VLEs are ones that have as their primary focus the communication between students and their teachers and between students and their peers. This communication is best generated through synchronous connections where there exists the ability to convey the student's immediate needs in real-time. Our research results and discussion will outline how a team approach that brings together teachers, students, administration, counsellors, mental health support staff, instructional designers, and ICT specialists is necessary to create a genuinely enriching VLE where both learning and social-emotional needs can be met. The authors present a case for further study in order to reveal the nature of the interaction among VLEs and student mental health.
\end{abstract}

Keywords Virtual · Education · Learning · Mental health · Face-to-face · Synchronous

\section{Introduction}

Increasingly educators are turning to digital online tools and resources to supplement and enhance their teaching in the classroom. Independent of the move to online learning as a result of the COVID-19 pandemic, there is a clear upward trend to the prevalence and variety of online learning opportunities available to students

Laura Caprara

leccaprara@gmail.com

1 Graduate Studies in Education, St. Francis Xavier University, Antigonish, Nova Scotia, Canada 
of all ages. In their meta-analysis, Means et al. (2009) show that the rise of online learning is for a variety of reasons:

Online learning has become popular because of its potential for providing more flexible access to content and instruction at any time, from any place. Frequently, the focus entails (a) increasing the availability of learning experiences for learners who cannot or choose not to attend traditional face-to-face offerings, (b) assembling and disseminating instructional content more cost efficiently, or (c) enabling instructors to handle more students while maintaining learning outcome quality that is equivalent to that of comparable face-toface instruction. (p. 22)

In Ontario, online learning can be accessed through traditional school boards using eLearning Ontario and Brightspace or through available online private schools such as VirtualHighSchool.com. These virtual learning environments (VLEs), online spaces that facilitate the delivery of curriculum content, assessment, and evaluation activities - deliver said curriculum in an asynchronous manner, that is "learning that is not delivered in real time. Asynchronous learning may involve students watching pre-recorded video lessons, completing assigned tasks, or contributing to online discussion boards" (Ontario Ministry of Education, 2020, PPM 164). This is different than synchronous learning which is defined as "Learning that happens in real time. Synchronous learning involves using text, video, or voice communication in a way that enables educators...to instruct and connect with students in real time" (Ontario Ministry of Education, 2020, PPM 164). It is believed that "synchronous learning supports the well-being and academic achievement of all students...by providing educators and students with an interactive and engaging way to learn. It helps teachers provide immediate feedback to students and enables students to interact with one another" (Ontario Ministry of Education, 2020, PPM 164). Despite this fulsome definition of synchronous learning, little research-driven policy or infrastructure exists whereby educators can be trained and supported in creating an ideal VLE for their students' educational and social-emotional needs (Jones, 2015; Kent et al., 2018). This was certainly the case for all Ontario educators when, in March 2020, schools were closed due to the SARS-COVID-19 global pandemic and learning shifted to online-only instruction as contextualised in the following section.

\subsection{Background}

On Thursday, March 12, 2020 at 4:00p.m. we tuned into the local news channel to hear that the Ontario Provincial Government was putting the province into lockdown to avert the upcoming threat of the novel Coronavirus, SARS-COVID-19. In this same news conference, we learned that Friday, March 13, 2020 would be our last day in schools; schools would be closed for two weeks after the March Break which began the following Monday. We spent the day photocopying, distributing, and explaining work packages for our students while ourselves wondering how we would negotiate the transition to distance learning and the new expectation to work - teach - from home. After these two weeks, a continuation of the lockdown was 
announced and Ontario educators were tasked with connecting with students and families procedure to gauge student's communications technology readiness, to monitor their social-emotional needs arising from the lockdown and to explain that basic emergency learning was now in place.

At the same time, educators were told to create virtual learning environments (VLEs) to deliver this emergency instruction. Hours of instruction guidelines were provided by the Ontario Ministry of Education (April 2020): for JK-Grade 6, no more than six hours per week; for Grades 7-8, no more than eleven hours per week and for Grades 9-12, no more than three hours per course per week. During this time, normal attendance procedures were paused and replaced with anecdotal teacher monitoring and the mode and delivery of teaching was not standardized via a specific virtual platform. Guidance from Ontario teacher unions was to avoid videoconferencing and webcasting (OECTA, 2020) to maintain the privacy of both teacher and student.

The unprecedented scope and unforeseen turmoil caused by the COVID-19 crisis resulted in a delayed and mixed response for how educators could meet the daily social-emotional needs of their students who were now being taught in ways that were not conducive to learning such as having no face-to-face communication. Part of this mixed response included the ministry directive that students' marks and grades would be frozen to the date prior to the initial closure (Miller, 2020), though opportunities for improvement would be provided. While the intentions of policymakers were rooted in compassion and wishing not to amplify any feelings of stress, anxiety, or hardship already being caused by the pandemic, it did not serve to inspire students to be continually engaged in their educational community or to feel wholly supported by said community. Overwhelmingly, students in both of our schools stopped engaging in course content; knowing that their grades could not change truly impacted their motivation, diligence, and general commitment to learning. When this disconnect occurred, teachers were advised to continue to call the student and encourage them to login to their VLEs, but this consistent check-in by four teachers at least once a week to each family began to feel at best like nagging and, at worst, an intrusion. This disconnect had another negative effect; now that students were not explicitly required to complete work for school, businesses were free to demand that they work throughout the day. Many students shared that they had taken on full-time hours at their part-time jobs. Had the student-teacherclassroom relationship continued throughout the closure somehow through routine, synchronous, live-video or live-voice communication, perhaps students and families would have felt a social and emotional pull to preserve their work habits and would have benefitted from helping to maintain the class community.

Essentially, our students went from daily, face-to-face interaction that built relationships and promoted positive social-emotional skills to the bare minimum interaction of a posting or an email a few times a week. Compounding this growing detachment was the social isolation that being in lockdown necessitated both from friends and family members who were at work. Students were at home, cut off from teachers, school, and friends, alone with the computer screens.

When schools reopened toward the end of September 2020, protocols and safety standards had been improved and implemented in ways that would encourage some 
families to opt for in-person learning while for others, the risk was still too great. For these families, school boards in Ontario created whole virtual schools or adopted a form of hybrid learning that would accommodate student from Junior Kindergarten through to Grade 12.

Our personal experience of in-person learning after the initial lockdown was atypical: though there was slight excitement the first day, this waned quickly and by the end of the week students were behaving very differently than they had been in March. Classes were silent; students were not speaking to each other, and group discussion or student-teacher conferences were very difficult to craft and nurture. In cases where students were priorly familiar with one another and the teacher, as was the case in one author's classroom, students remained quiet, distanced, and generally withdrawn. These personal observations were similarly attested by several colleagues. For one author who had been assigned to the new virtual school, similar observations were made. Here, students from all over the city were being placed in VLEs together, disconnected from their home schools. Every attempt was made to create positive community bonds but still, save a handful of eager students, online classrooms were quiet both auditorily and in the chat box.

Unfortunately, COVID-19 continued to spread rapidly through the province and by the winter of 2021, the threat of the new, more infectious variants of COVID-19 forced the hand of the Ontario Ministry of Education to close schools once again for the remainder of the school year. The most marked difference in this lockdown is the continuation of the collection of attendance - students are at least driven to login to their VLEs to have their attendance recorded to avoid the consequences of truancy. Many students have shared with the authors that this second lockdown had evaporated their hopes of any social-emotional normalcy for their educational experience. They have attested that they are tired of feeling alone, overly challenged at the thought of having to continue their learning experiences solely through their computer screen.

\section{The path to inquiry}

In the summer of 2020, The Hospital for Sick Children (2019) released a report that detailed how online learning and increased screen time could result in an increase of negative mental health effects. In addition, the prevailing advice of Public Health Ontario (2015) for the total number of hours of screen-time children and youth should be engaged in had not moved from the recommended "no more than 2 hours per day". Instead of heeding the warning and advice of these public institutions, the Ontario Ministry of Education Policy/Program Memorandum No. 164 (2020) defining synchronous learning as "using text, video, or voice communication" in real time, set in place the following expectations for daily synchronous learning: $180 \mathrm{~min}$ for Kindergarten and 225 min for Grades 1-12.

Our desire to study the mental health effects of online learning takes its root in the experience of students and their guardians who have directly voiced difficulty with engagement in online schooling. Specifically, our students shared that their experiences in courses facilitated by teachers who did not utilize real-time video for the delivery of their synchronous lessons were difficult, hard to manage, and at times felt alienating. 
Certainly, the few noted anecdotes above cannot constitute a direct cause for this review. Nonetheless, it is the view of the authors that such comments appearing from within the unique context of the mandated and sweeping switch to online learning warrant an investigation of what research might exist to establish acceptable standards of VLE implementation. In the case of the COVID-19 context, it must be understood that the changes to educational architectures were motivated by the physical requirement of stopping the spread of disease rather than what research has shown to be the best mode of education for the learner and their mental health needs. Further, even within the confines of mass VLE implementation, deeming the use of real-time video as strictly optional instead of prescribing a definitive modality for engaging in best practice displays a gap in an understanding of VLE significance. Further still, as online learning continues to be a the only viable option for many families, educators in Ontario must ensure that the creation of a VLE and the curriculum delivered through it is guided by the Ontario College of Teachers (OCT) Ethical Standards of Care, where it is understood that Ontario Teachers ought to avoid practices that may not support the welfare of all students placed in their care.

The Ontario College of Teachers (2020) defines the ethical standard of care as follows: "Members express their commitment to students' well-being and learning through positive influence, professional judgment and empathy in practice." Further, the Ontario Education Act, 1990 Sect. 264(1c) clarifies that part of a teacher's duty is to impress the "highest regard for...humanity... and all other virtues" to their students. In addition to the duty of a Principal to provide "assiduous attention to the health and comfort of the pupils" (Ontario Education Act, 1990, Sect. 265(1j)) they must do so in such a way that they set the standard for the teacher. Without daily, live interaction with students, how is it possible to wholly meet these expectations?

Interestingly, the concept of all persons having to remain at home during the new COVID-19 online education paradigm seemed to create a vague understanding of whether it was even possible for the professional liability of care to take place. In consideration of the area of attendance, it must be understood that the traditional taking of attendance has a layered purpose: to ensure the "safe arrival" of students, to give proof of student attendance for funding allocation, and to link a student to the legal liability of a teacher as well as to allow teachers to exercise interventions for students who are truant. In the first stage of lockdown, teachers were asked to not take attendance and so were unable to ensure regular student contact. In this way, it became much more difficult to distinguish which students were not able to keep up with their studies and who required appropriate interventions for their learning, development, and wellness.

Tronick et al. (1978) showed that when the face-to-face interaction between infants and their mothers becomes distorted in such a way whereby the mother is unresponsive and still, "infants reacted with intense wariness and eventual withdrawal" (p. 1). They concluded that it was vital to have "interactional reciprocity" (Tronick et al., 1978, p. 1) to learn how to regulate their own emotional reactions. In their meta-analysis of this Still-Face Paradigm, Mesman et al. (2009) found that not only had the paradigm been consistent through multiple studies in infants, but its negative effects could also be found in both youth and adults. Experiments with adults resulted in "quite severe disrupting effects on social interactions, making people angry, confused, or upset...[where] [t] he perceived necessity for following the 
ground rules of social interactions is likely to stem from the evolutionary roots of human social life" (Mesman et al., 2009, p. 156). These results would suggest that part of the educator's duty of care to a student is to maintain this quintessentially human behaviour of consistent face-to-face interaction. Without this fundamental interaction, it seems that humans are unable to properly regulate their emotional expression. Certainly social-emotional learning and the formation and maintenance of positive relationships with others is a core part of the care mandate of teachers.

\section{Purpose of scoping review}

While it could be surmised that the guiding education authorities' combined lack of clarity in declaring best practice directives and providing systems of care contributed to negative student experiences, the notion of how these organizational failures might have impacted student mental health must be drawn into focus. Indeed, the most notable shift in education has been toward the use of the online classroom and it is foreseeable that the continuation of this paradigm will be unavoidable. However, with the ambiguous messaging that surrounds that which defines quality implementation of a VLE, there lies a discernible gap in gauging the importance of teachers using live video in the delivery of synchronous instruction and if significant mental health implications are present in the decision to do so.

The purpose of our scoping review is to isolate and investigate the existing data and research that identifies if the real-time visual presence of a teacher in a VLE is a significant factor in a student's ability to maintain good mental health. Such research might reconcile the void of definitive directives educational authorities have offered concerning teachers' utilization of real-time video in a VLE and, more importantly, provide students with a higher standard of care while enduring the context of increased vulnerability the pandemic has introduced.

In short, this scoping review aims to answer two questions:

1. Does the synchronous face-to-face and interactive presence of a teacher in a VLE contribute positively to student learning and mental health and well-being?

2. What are the characteristics of a VLE that meets the social-emotional care requirements and needs of the student?

\section{Method and parameters}

This scoping review works to capture the current "size and location of the literature" (Anderson et al., 2008, p.7) to better define the state of understanding of our research questions. Further, it is our hope that this scoping review might work to ascertain common threads among the research and note any gaps to inspire further inquiry in the topic. All of the material will be charted so it can be viewed in tandem for the above purposes. 


\subsection{Boundaries of the review}

Our search was limited to English-only peer-reviewed research literature that investigated the efficacy of online teaching and VLEs for educating the whole student. More specifically, we completed a search of all research articles published between 1 January 2010 and 31 January 2021 (an 11-year period). The rationale for focusing on this span of just over a decade was to draw our attention to the most recent research evidence related to our question. This date range also reflects the time span in which we had secured permanent work as educators; tracing the development and evolution of online learning since that point is of great personal interest.

Our search utilized the following terms: virtual learning environment (in all text) OR online instruction (in all text) AND mental health (in all text). These search terms were selected as they provided the widest catchment for the screening process required for this scoping review; in particular, the search term virtual learning environment was selected to identify research that was specific to an interactive context of online learning, as opposed to, for instance, online learning structured as a correspondence course. Databases that we utilized include ProQuest, ProQuest/ERIC, APA PsychINFO, and SAGE Journals Online because together they encompass a comprehensive and diverse catalogue of education-related literature as well as research regarding the psychological aspects of education. These database searches occurred between January 31, 2021, and February 7, 2021.

\subsubsection{Special considerations of the topic search: defining a student}

Ideally, the search terms could have been narrowed to refer to students specifically in a high school setting, using common platforms such as Google Classroom, but these terms did not yield any results. In an effort to compile the most useful sources for our research, a broadening rather than narrowing approach to our search terms was employed as it was discovered that limited resources existed in the field we were exploring. Considering this, the limits we set required special considerations of demarcation. For instance, many sources pertaining to the student mental health in a VLE context dealt exclusively with nursing students (e.g., Shea \& Rovera, 2021). These studies offered excellent data sets but were omitted because the data could not be understood as congruous with a universalized definition of what constitutes a student. That is, the specialized nature of these studies involved students who had the responsibility of dealing with patient care, using VLEs to interact with their patients. In this way, the nursing paradigm muddied the demarcation between the VLE experience of a student and that of an authority.

\subsection{Inclusion criteria}

In initially assessing and screening the results of the database searches, we ventured to remove sources that did not pertain to the contexts of VLEs and the student's experience of those VLEs. Here, a primary list of 268 articles was redacted to a sum of 63 articles via an evaluation on the content of the title and abstract of each article. The 
inclusion of the remaining 63 articles was based on their titles and abstracts having expressed: (1) the use of an online modality that would implicitly involve the visual presence of an educator, and (2) the interest in the contexts of the learners' experiences being a result of the instruction provided. Sources that were concerned with the experience of post-secondary students were only included if they involved Year 1 students as part of their purview. This limit was imposed on the research as we perceived this domain of data as relevant to the prospect of constructing an information-set surrounding the transitional stage of Grade 12 into post-secondary. Further, this inclusion might allow for a greater basis of insight into the still emerging reality of widespread online education. Notable exclusions from the research that might have helped develop such a picture were many articles that focused on the VLE experiences of graduate and post-graduate level students (e.g., Chugani \& Houtrow, 2020; Gardner, 2020; Shawaqfeh et al., 2020) and articles concerned with the mental health of educators who utilized VLEs (e.g., Watermeyer et al., 2021; Rowe et al., 2020; Ault et al., 2020; Alkarani \& Thobaity, 2020; Schlesselman, 2020). The subsequent 63 articles were read in their entirety to determine whether their content would be appropriate for this scoping review. This stage of assessment resulted in the inclusion of 38 articles.

\subsection{Manual inclusions}

Additionally, a reference check of all 38 articles yielded the inclusion of a meta-analysis authored by Cavanaugh et al. (2004) we deemed relevant insofar as it provided an overview of the effects of online learning in a strictly academic sense allowing a possible comparison between achievement and positive mental health. A manual search conducted prior to the exercise of prescribed database search-terms warranted the inclusion of one other meta-analysis authored by Mesman et al. (2009) which is noted in the introduction section of this scoping review. The specific data and information presented in the work of Mesman et al. (2009) serves as a correlational tool in observing the trends apparent in the included articles. As a final article addition, a second manual journal search was conducted where two studies were found to include data that encompassed student perceptions of their experiences with VLEs, thus, resulting in a total sum of 42 articles to be included in this scoping review. The total review process is noted visually in Fig. 1.

\section{Summary of research findings}

The purpose of this scoping review is to isolate and investigate the existing data and research that identifies if the real-time visual presence of a teacher in a virtual learning environment (VLE) is a significant factor in a student's ability to maintain good mental health. Overall, our research has shown that authentic, high quality VLEs are ones that have as their primary focus the communication between students and their teachers and between students and their peers. This communication is best generated through synchronous connections where there exists the ability to convey the student's immediate needs in real-time. The demands placed upon an individual 


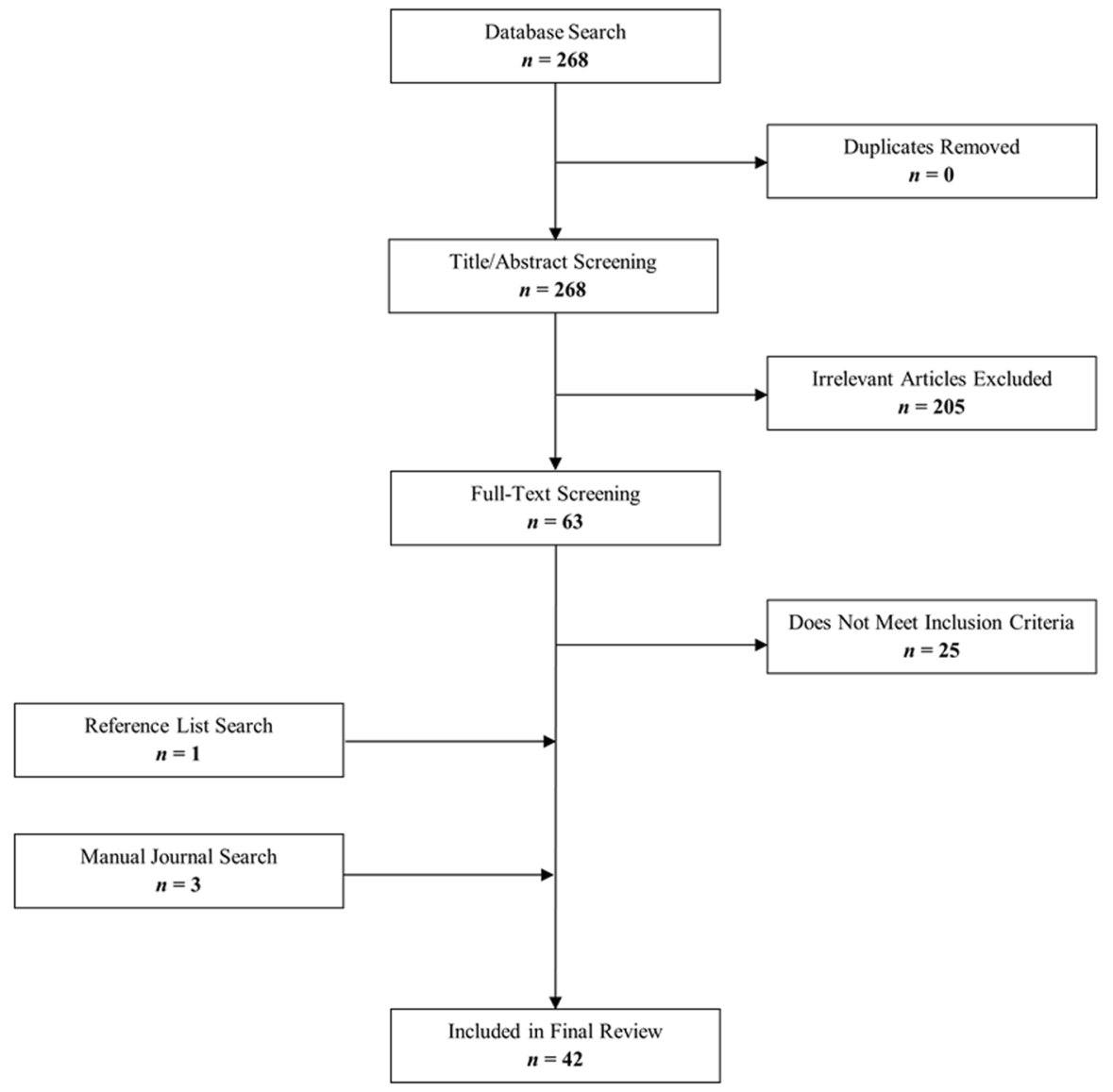

Fig. 1 Review process and results

educator to facilitate an online education for students, inclusive of the creation and maintenance of an effectual and engaging VLE often serving as a proxy to a faceto-face (F2F) base-school, "require[s] extensive time commitments" (Wingo et al., 2016, p. 437) which are far beyond the standard workload formulas calculated by many institutions (Wingo et al., 2016). Indeed, the complexity of this task while also providing sufficient social-emotional services for students and families is not fully understood in terms of student and teacher equity. Our research results and discussion will outline how a team approach that brings together teachers, students, administration, counsellors, mental health support staff, instructional designers, and ICT specialists is necessary to create a genuinely enriching VLE where both learning and social-emotional needs can be met.

Summaries of the 42 articles pertaining to this research are provided in Table 1. In addition to information related to authors, years of publication, countries (i.e., where the research was conducted), participant profiles, intervention programs and 
timelines (where available) and data sources, we have also summarised the researchers' aims, research designs, findings, and conclusions.

Our research provided studies that had been conducted from nearly every continent of Earth, save South America and Antarctica. Notably, many of the articles were completed by researchers in the United States $(n=16)$. Fifteen were completed by researchers in Europe (Belgium, Cyprus, Georgia, Germany, Greece, Poland, Portugal, Slovenia, The Netherlands, Turkey, Ukraine, and the United Kingdom), and six were completed by researchers in Asia (India, South Korea, Taiwan, and Vietnam). The remaining research was conducted in Australia, Canada, Jordan, and Kenya. The research designs employed by the various researchers in our summary are quite varied and sometimes particularly nuanced and range from case study to meta-analysis. However, a preference for experimental, quasi-experimental, qualitative analysis, and mixed-method correlational analysis did emerge. Overall, few articles had a singular focus, which can be attributed to the expansive field of VLEs and their many intricate pieces. Some central concepts were highlighted, however, in the research: fifteen observed the effectiveness, benefits or challenges of some aspect of VLE (i.e., using virtual reality simulations or synchronous video); ten investigated student readiness, either on a social-emotional basis, technology know-how, or academic; six focused on the mental health of the learners in VLEs; six gathered data on the experiences and perceptions of either students, students' families, or faculty, and four researched the current infrastructure and available policies for online learning. The participant profiles of our research were also quite varied, identifying elementary and secondary school-aged children, both undergraduate and graduate students, school faculty, and student family members, sometimes all within the same study.

Our research results have been organized in Table 1 below. It has been constructed in such a manner whereby an informational narrative that reflects the essential themes found within the research can be revealed.

\section{Results and discussion of themes}

The articles included in Table 1 represent the most current and relevant research in considering the embedded inquiry of this scoping review which involves uncovering the nature, implications, and best iterations of practice within VLE contexts. In our reading and review of the data therein, the themes of insufficient data surrounding VLEs, VLE benefits, the challenge of VLE readiness, and that which constitutes the ideal VLE emerged as pivotal. The objective of this section is to elucidate these themes, thereby, providing a modest basis for recommendations regarding VLE implementations and, perhaps, a view to offer directionality for future research.

\subsection{Insufficient data}

A key note thread found within many of articles was the self-admission of insufficient data. This theme of insufficient data is expressed in varying capacities that 


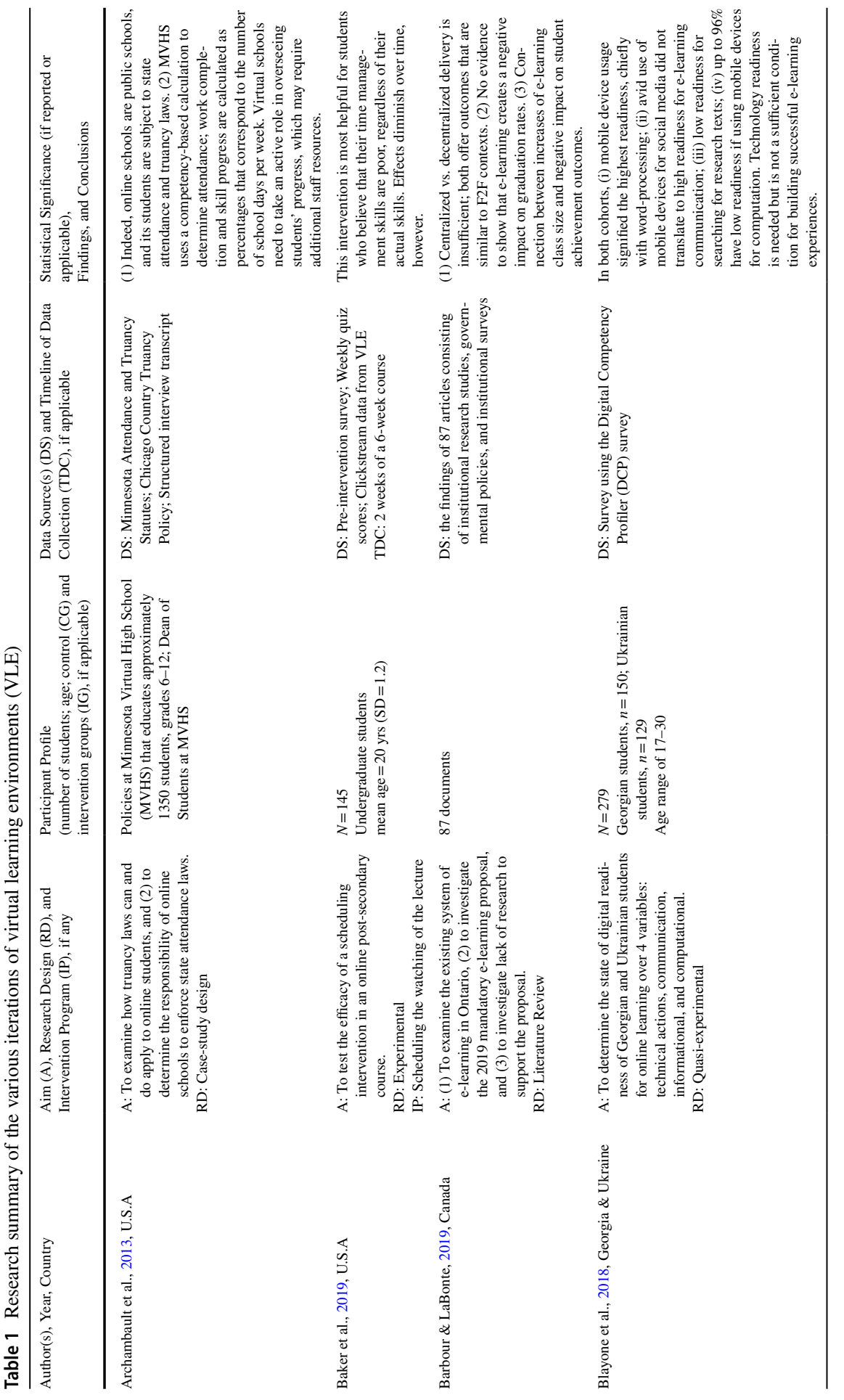




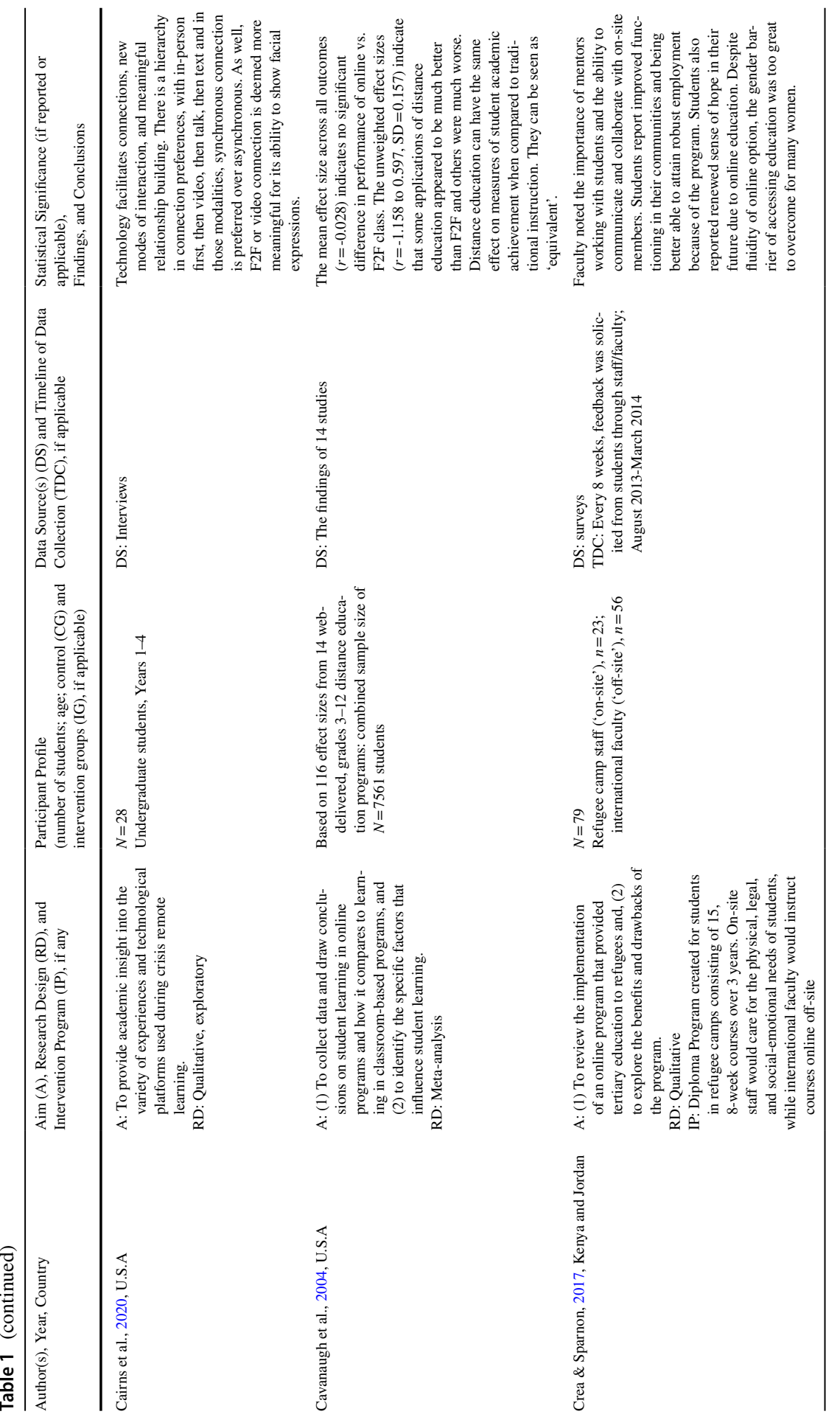




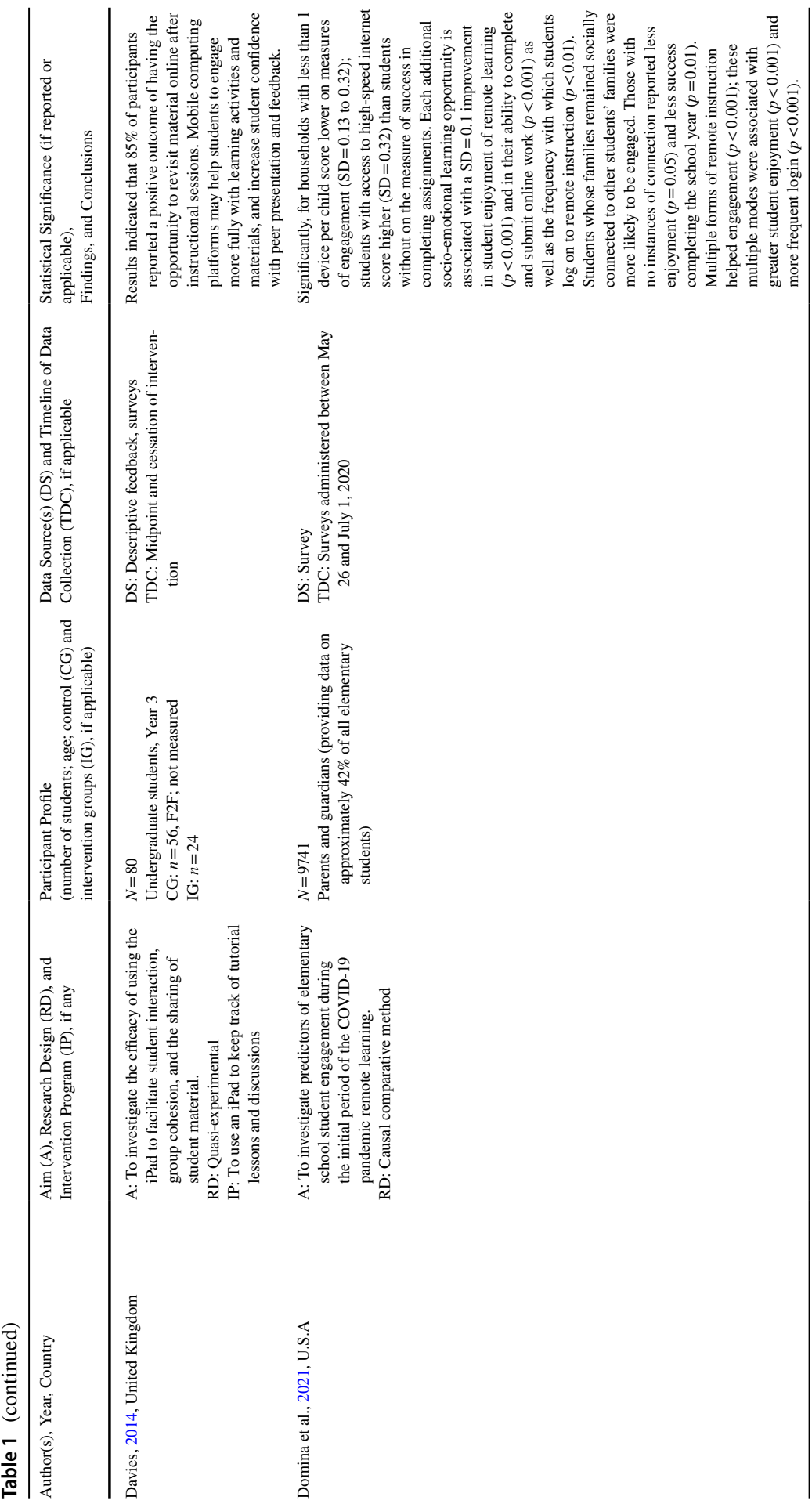




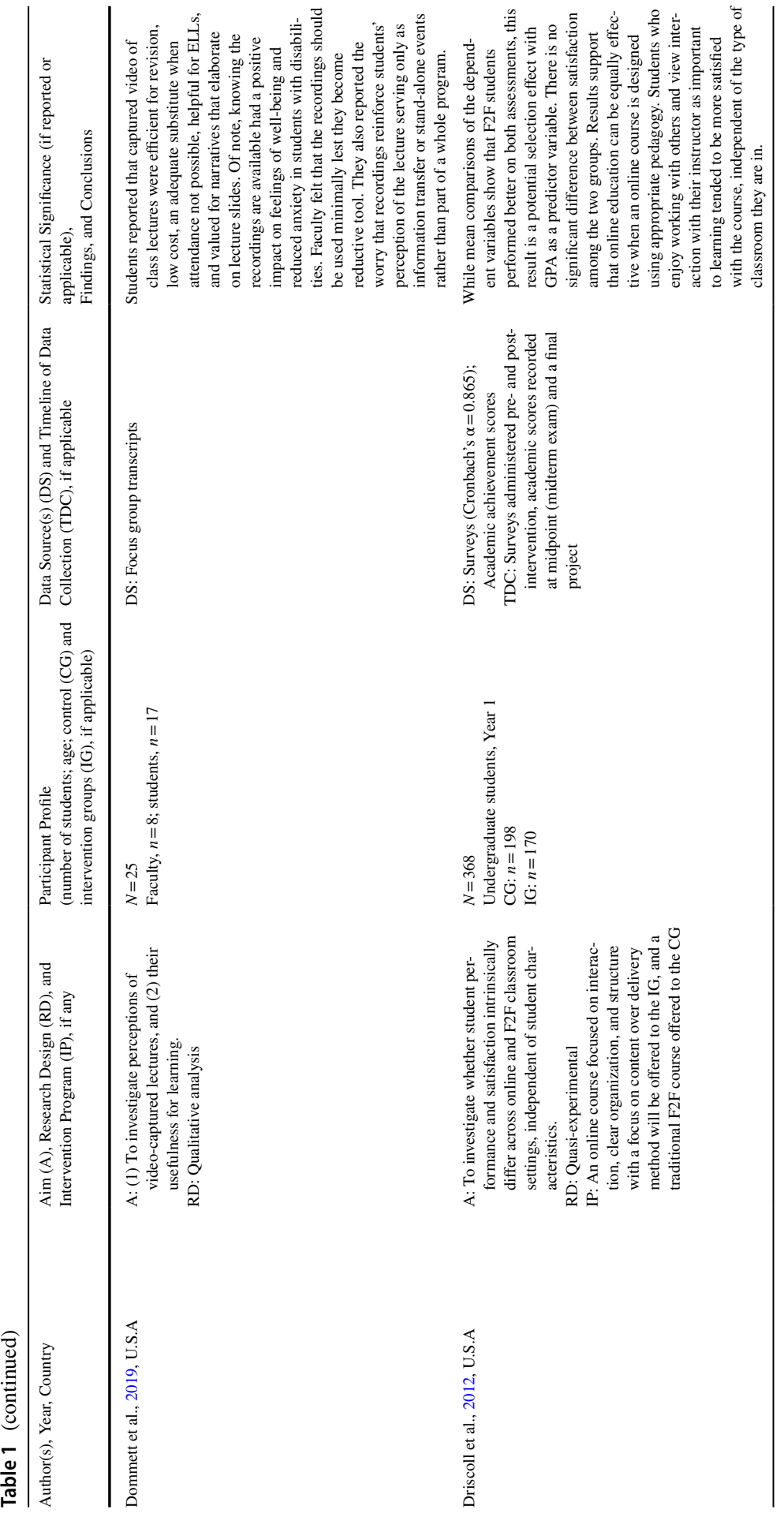




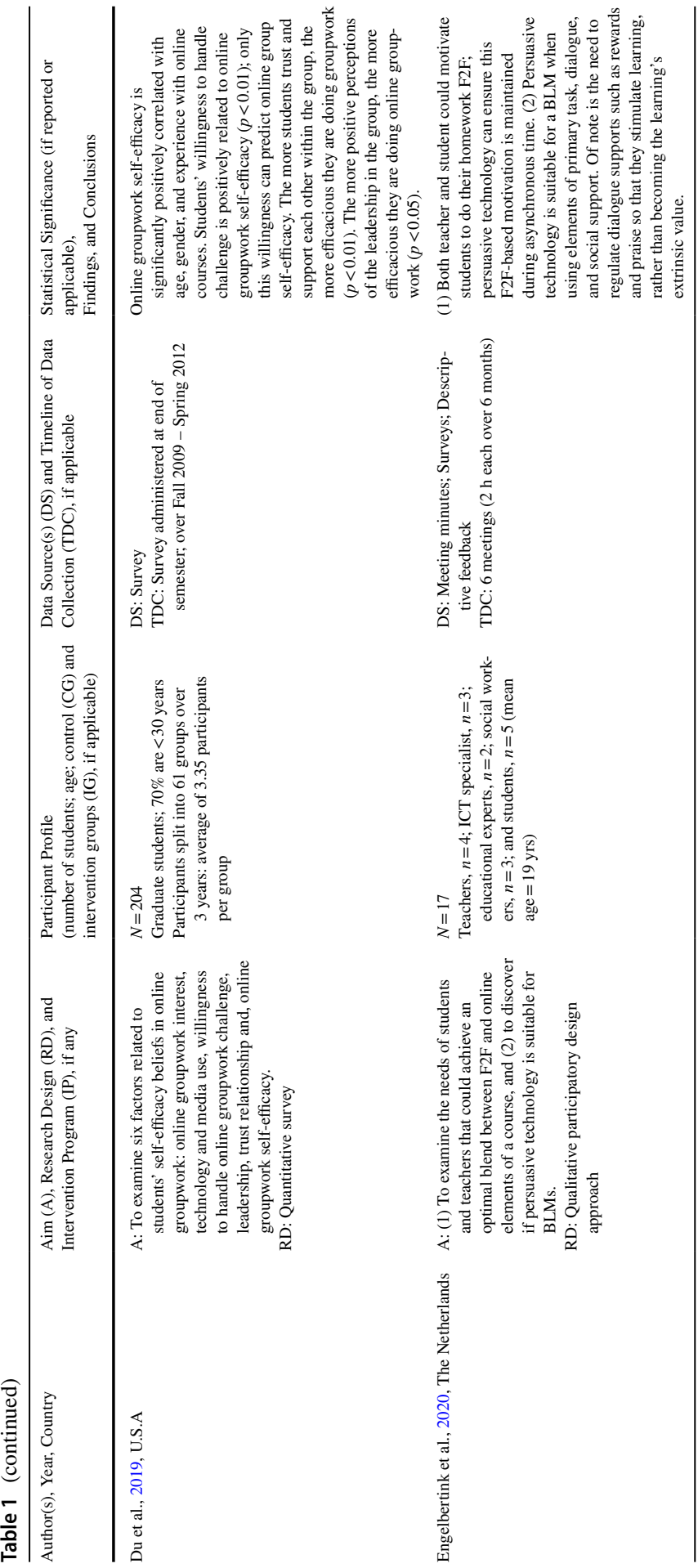




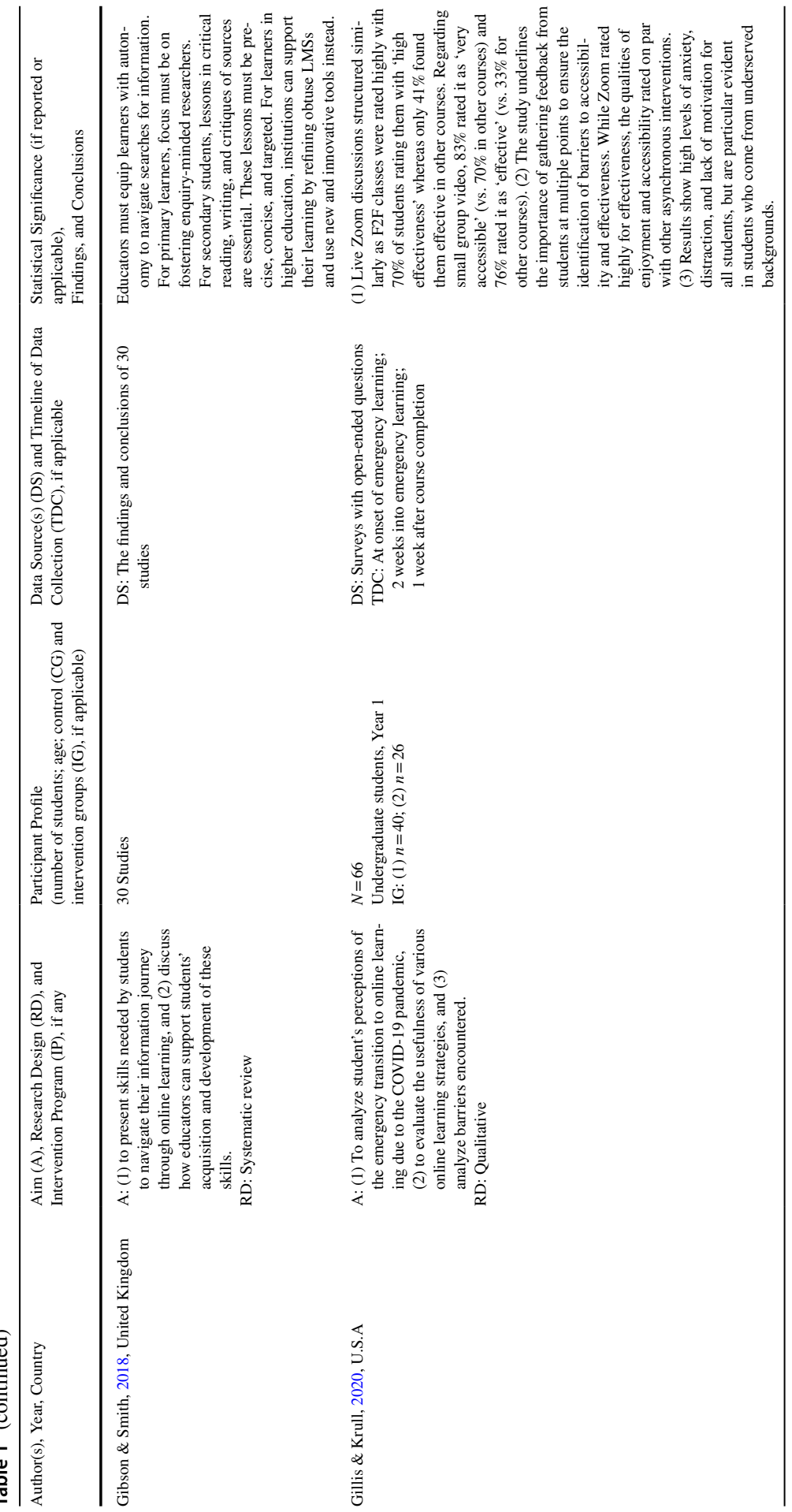




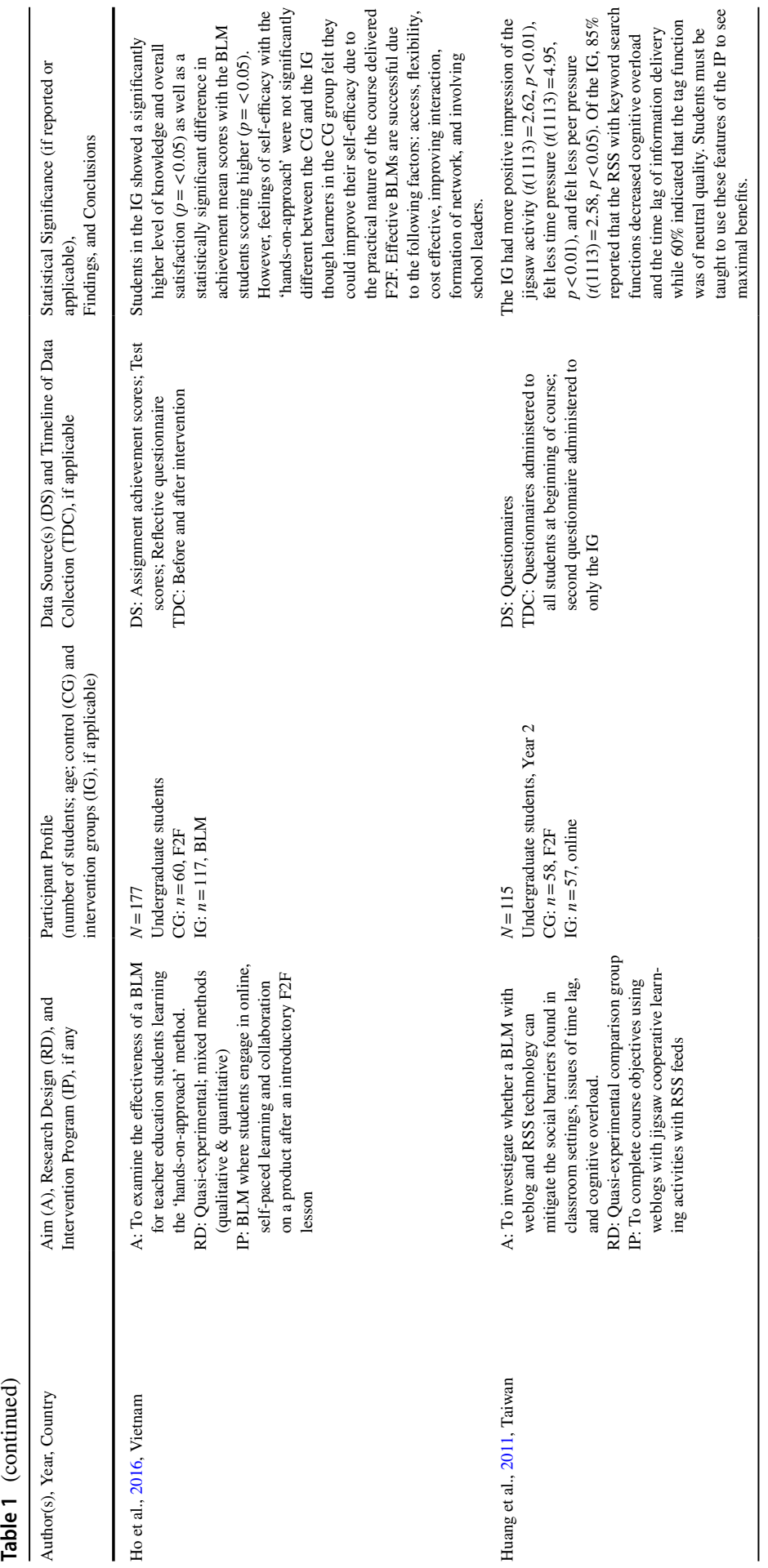




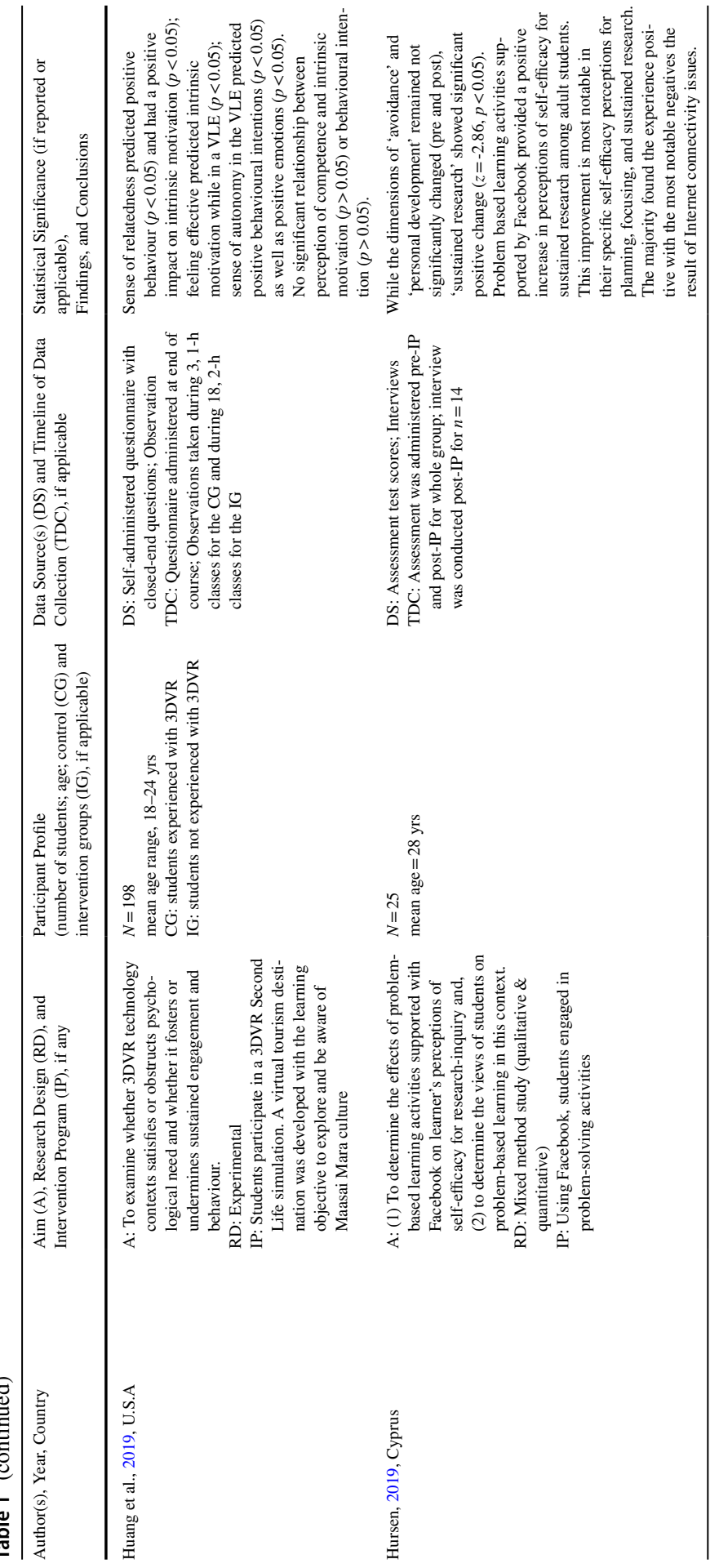




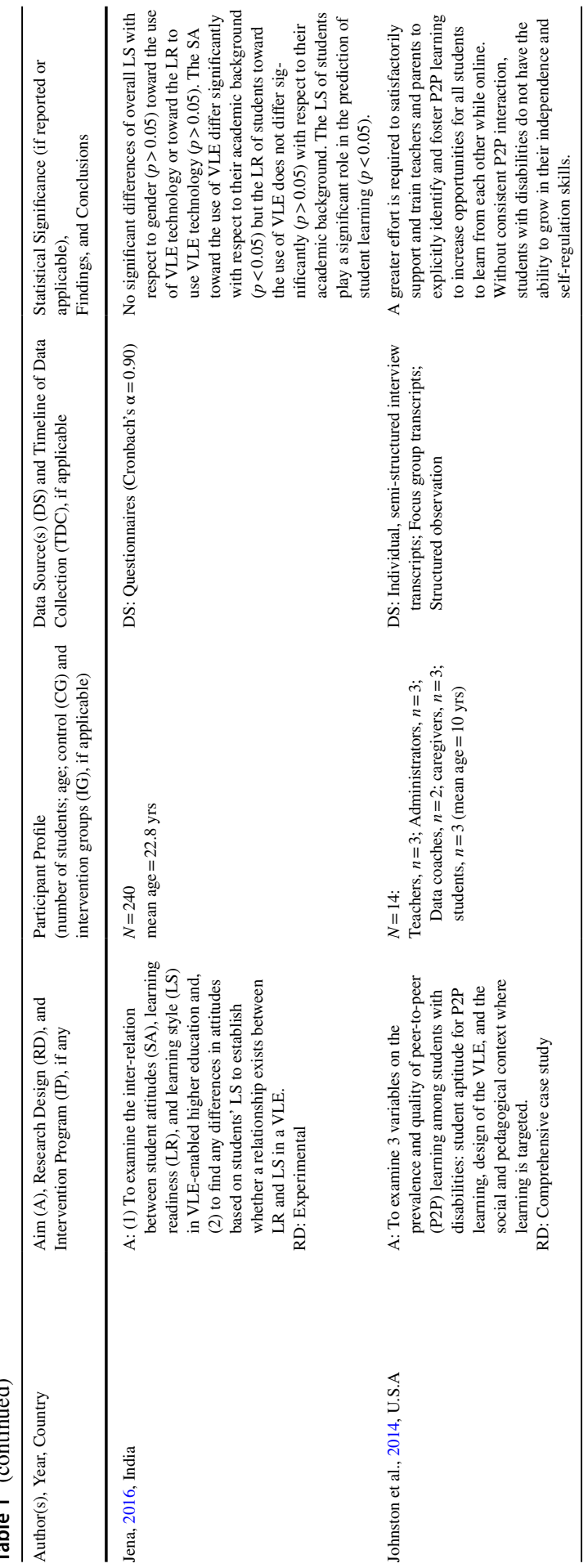




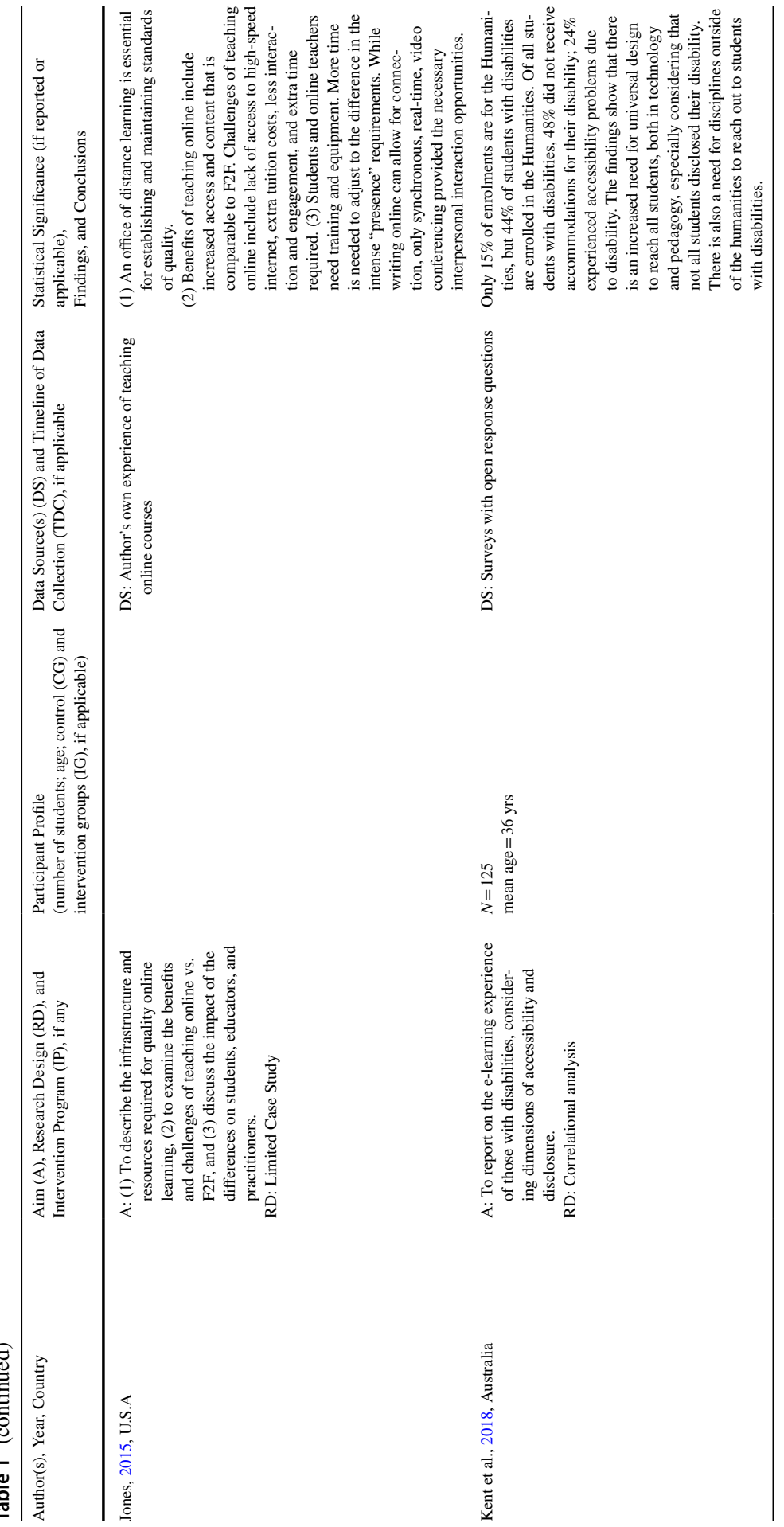




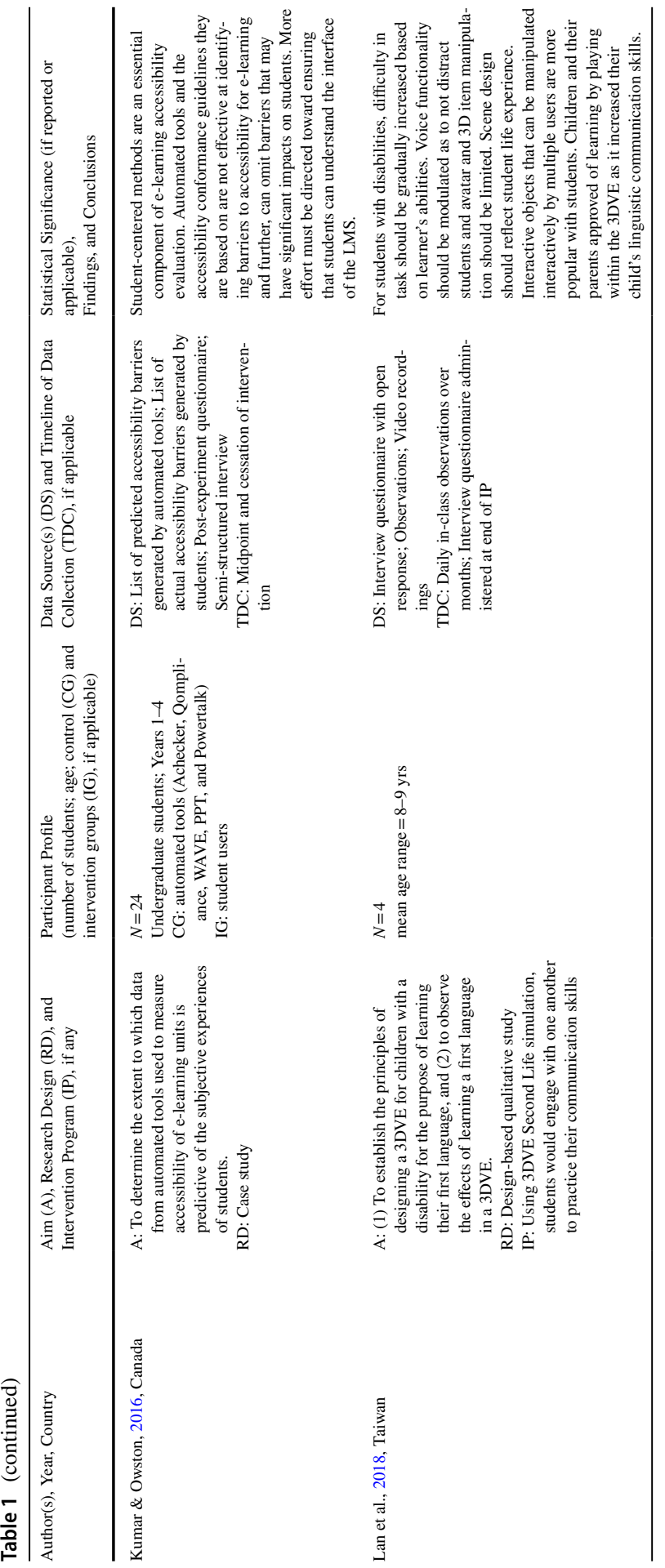




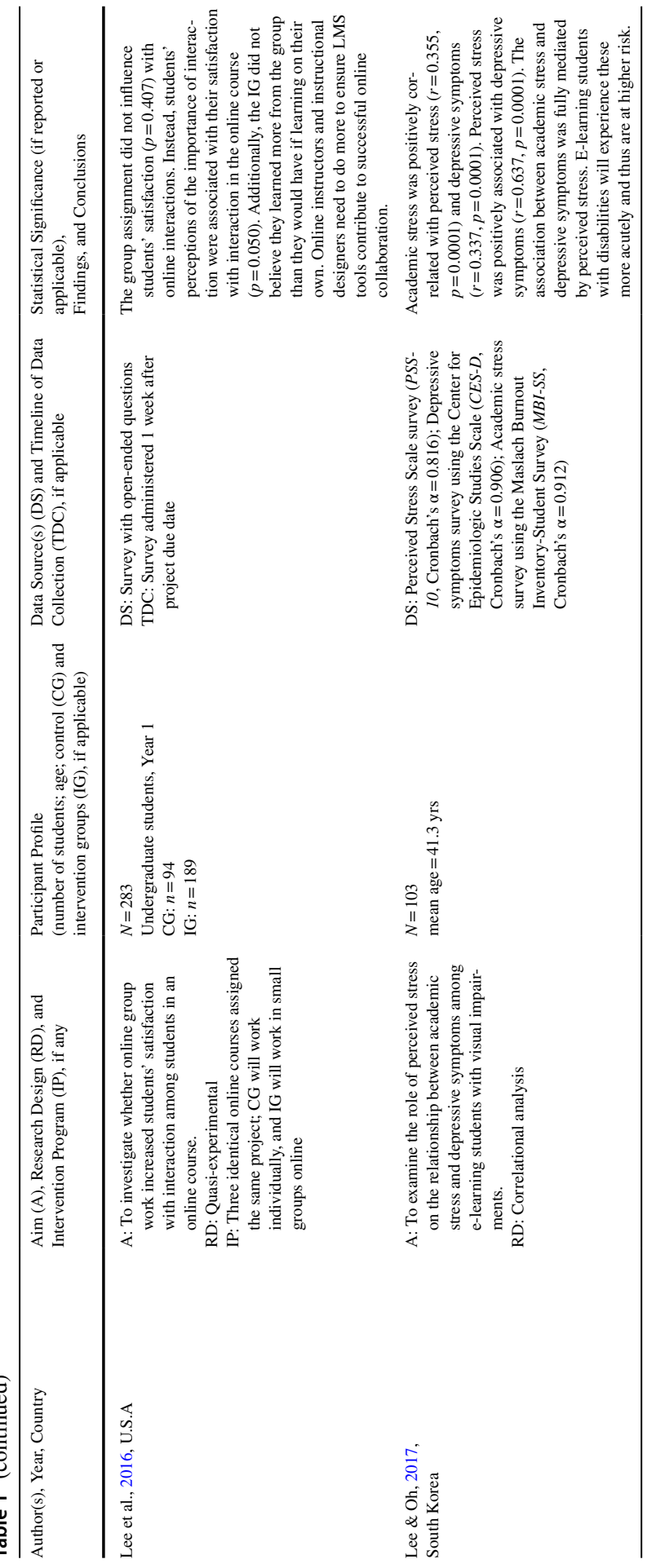




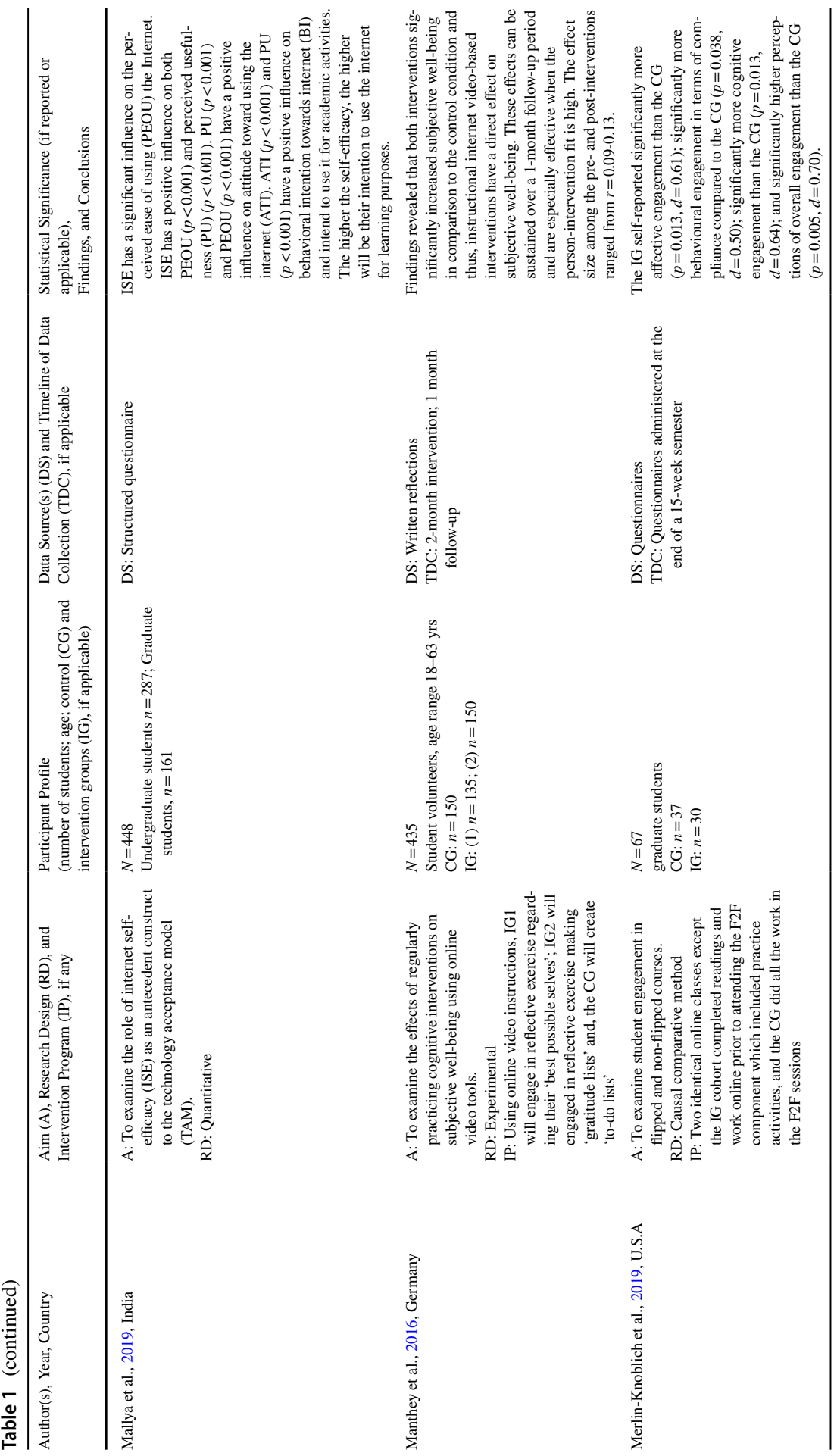




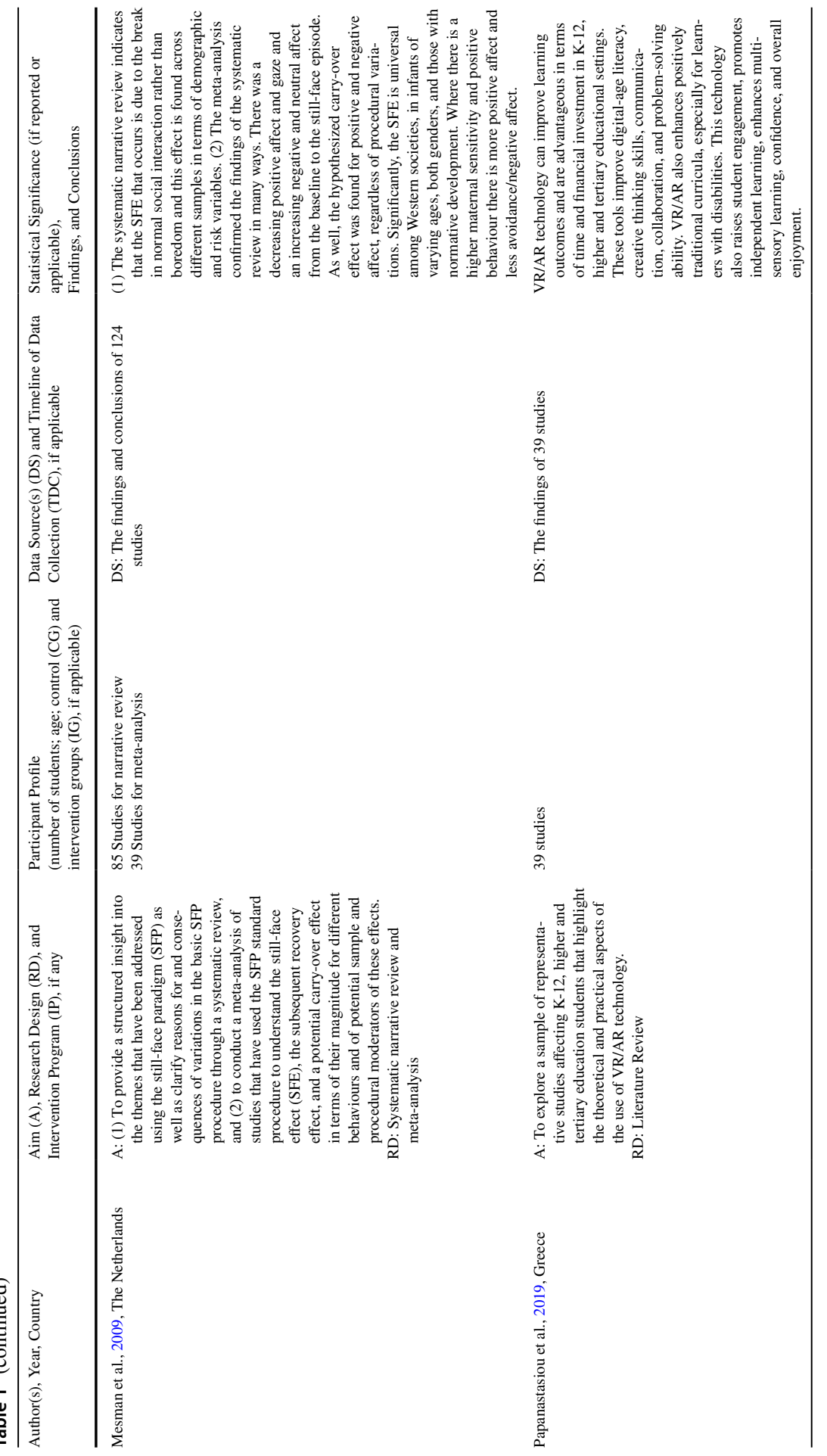




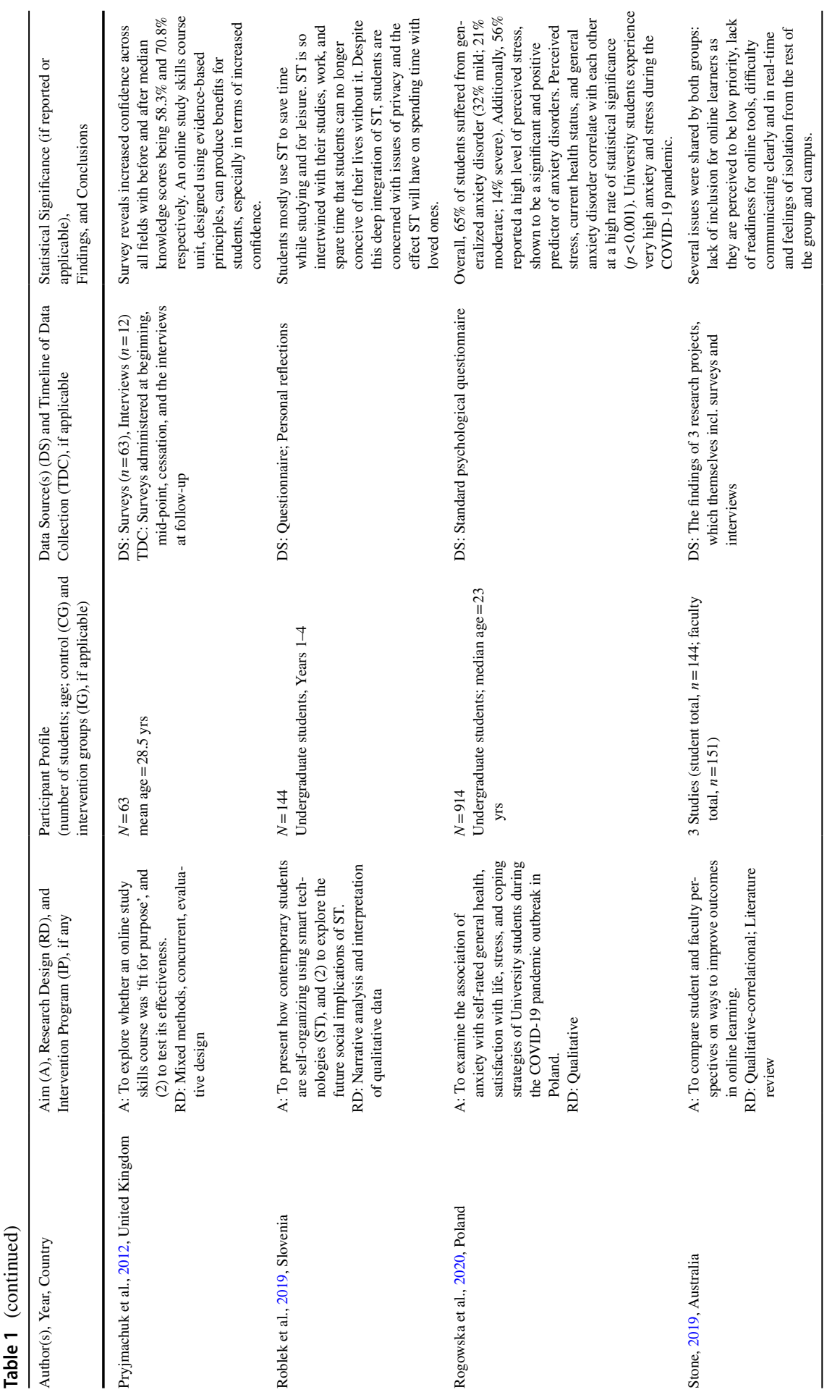




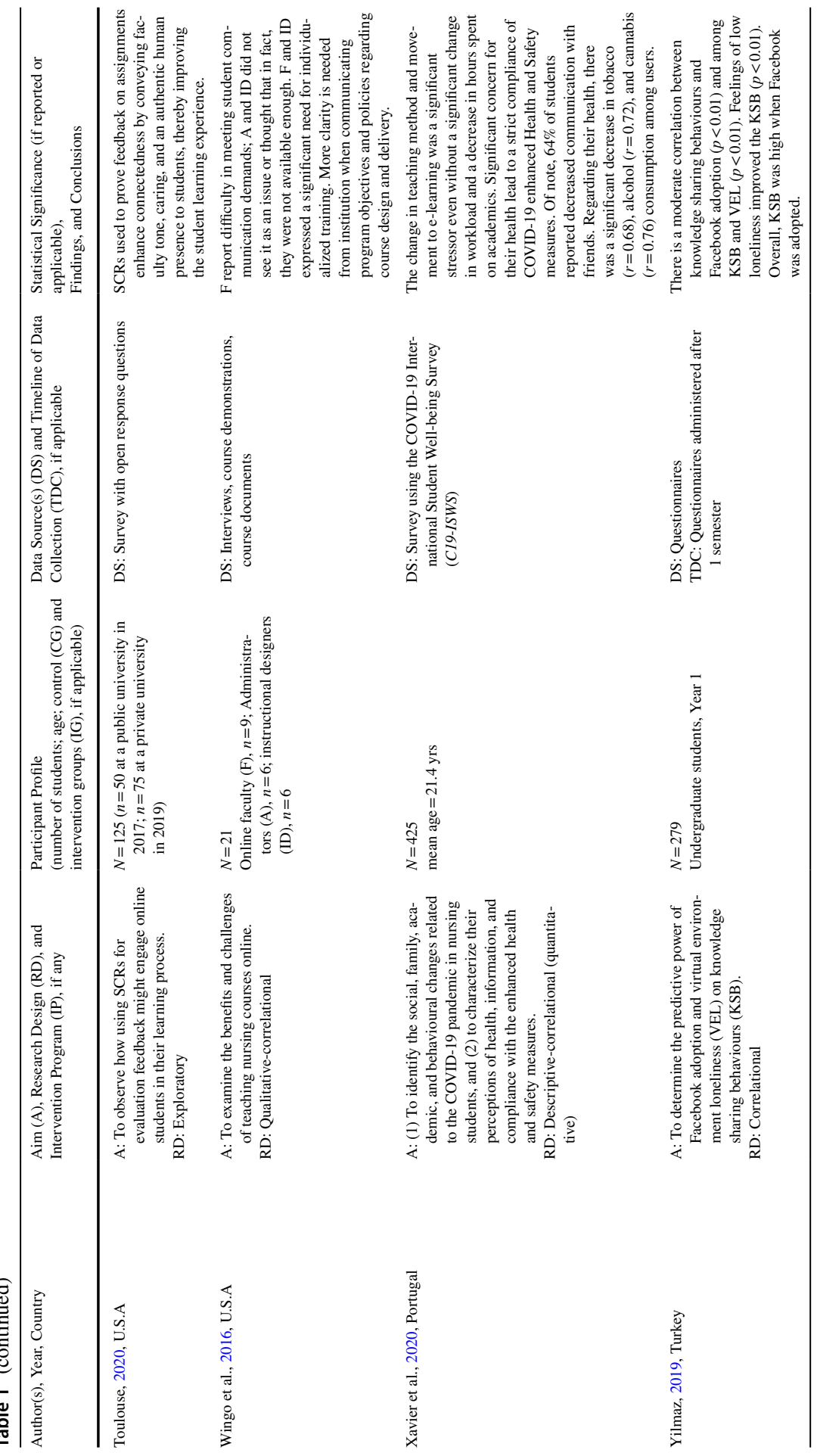




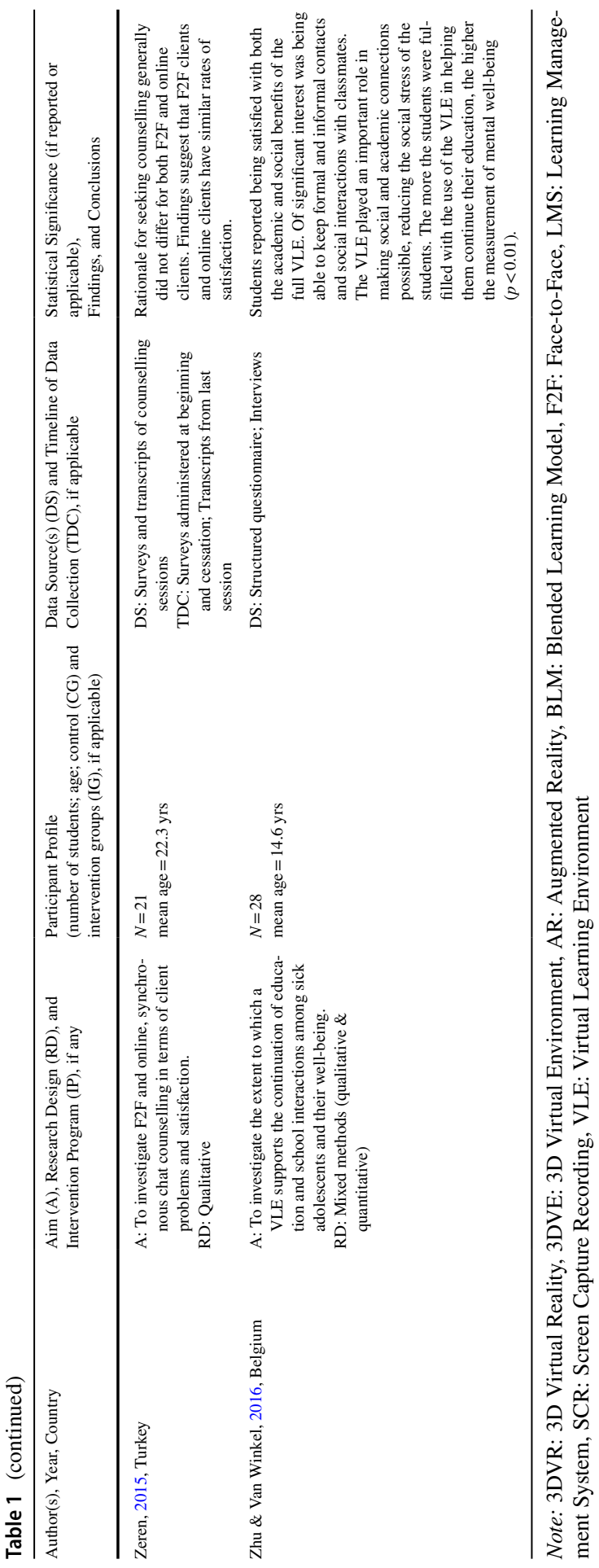


range from claims of there being a limited or even non-existent body of research, to more systemic causes for the insufficiencies. While the lack of data is often presented as a cautionary device for the demarcation of limits to implementation outside the context of the studies and provide exhortation for further research to be conducted, the admissions of insufficient data also point to the novel nature of the area of inquiry in question. Kumar and Owston (2015) begin their study on e-learning accessibility by stating that their field of inquiry had "not been explored, nor have methods to generate data" (p. 264) expressing that there is "a dearth of studies" (p. 268 ) in the literature, and concluding that "[c]ontinued work in the area of developing methods to evaluate e-learning accessibility is thus urgently needed" (p. 280). Archambault et al. (2013) also identified their research scope of basic virtual school policies as being novel in nature, having no representation in the existing literature. Many researchers make note of the existing data as being too insufficient to draw more universal conclusions (Barbour \& LaBronte, 2019; Cavanaugh et al., 2004; Engelbertink et al., 2020; Gillis \& Krull, 2020; Ho et al., 2014; Jena, 2016; Zhu \& van Winkel, 2016). In addition to this paucity of research, the attrition of study participants is noted as being a barrier to gathering full data sets (Manthey et al., 2016).

Some systemic issues which led to shortages in the available data are noted in Johnston et al. (2014) where school districts are slow to institute policy. Cavanaugh et al. (2004) mentioned a similar dynamic in considering that common goals are needed in policy making to identify the effectiveness of an intervention and policy makers and evaluators are exhorted to work together in partnership to ameliorate this. A further systemic barrier to data production that is noted is the problem of implementation of programming without conducting research (Cavanaugh et al., 2004).

\subsection{Benefits of VLEs}

In response to our first research question regarding the benefits of a wholly synchronous VLE experience, the research is generally favourable toward academic achievement with some degree of attestation to its social-emotional benefits. The benefits to VLEs and their implementation are assumed among most of our research in how they can be potential vehicles delivering some form of meaningful intervention or program within a given context. Further, some of the articles underline fundamental goods that can be uniquely exploited via VLEs. Driscoll et al. (2012) cites VLEs as an opportunity to better promote a constructivist framework for learning in saying that it inherently "creates a structural impetus for this style of learning that is not automatically present in F2F classrooms" (p. 314). Cavanaugh et al. (2004) provides multiple examples of how the institutional advantages of virtual schools "represent the best hope for bringing high school reform quickly to large numbers of students" (p. 22). Building upon the pervasive benefits to VLEs as a concept, Roblek et al. (2019) frame VLE dynamics as an essential component of human advancement where "social relations will be formed through the building of collective intelligence" (p. 96). Similarly, VLEs and their relation to ICT literacy as a global objective is observed throughout the research (Blayone 
et al., 2018; Cavanaugh et al., 2004; Crea \& Sparnon, 2017; Davies, 2014; Gibson \& Smith, 2018; Huang et al., 2011; Hursen, 2019; Jena, 2016; Mallya et al., 2019).

The strengths of specifically synchronous VLEs emerge in the research with highlighting synchronous learning as an essential component to student engagement with technology, peers, and educators. Concerning technology fluency, even in a blended learning context, synchronous VLEs offered a unique opportunity to implement technology in a meaningful way (Ho et al., 2016). Using a device in a synchronous context meant that students felt more engaged with material, subsequently feeling more confident with presenting work using technology, and students enjoyed being able to revisit an interactive lesson digitally after the synchronous session was over (Davies, 2014; Driscoll et al., 2012; Kumar \& Owston, 2016). In terms of supporting engagement among classmates, synchronous learning was seen to offer increased avenues for peer-to-peer learning while allowing for teacher involvement throughout, thus increasing effectiveness (Crea \& Sparnon, 2017; Johnston et al, 2014). Synchronous VLEs that include video also offer opportunities to be present to a class setting in a way that attends to learning retention, academic engagement, resiliency, and self-regulation (Archambault et al., 2013; Driscoll et al., 2012). When VLEs employ best-possible real-time communication, education processes can be more active, constructive, cooperative, and more attentive to a student's meta-cognitive abilities than the traditional classroom (Cavanaugh et al., 2004). These latter points concerning real-time visual instruction potentially align with a foundational dynamic noted by Mesman et al. (2009) where it is stated that an "infant needs an external regulator to achieve optimal arousal levels and will show disorganization of emotion and behaviour when the regulator is absent or non-optimal" (p.122). Such a relationship becomes apparent in the work of.

Baker et al. (2019) which observed quiz results decrease among those students whose instructor withdrew communication and synchronous availability after originally being quite attendant to their needs and in the work of Engelbertink et al. (2020) where student motivation dropped significantly when the teacher no longer demonstrated an interest in the student's homework. Throughout the research, it is evident that student engagement and achievement is well-supported in a synchronous VLE.

\subsection{The barrier to a VLE: the challenge of readiness}

Across all our research, it became clear that one of the primary factors curtailing the effectiveness of any VLE or LMS was the various states of readiness of the institution, the teacher, and the student.

At an institutional level it can be said that most schools are not equipped to create VLEs where students can thrive, even those schools that are virtual by design. The infrastructure required to create a holistic learning experience for the student, and one that embodies fair and equitable working conditions for the online educator, requires a considerable investiture of human resources and technological tools (Archambault et al., 2013; Cairns et al., 2020; Jones, 2015). Many LMSs that institutions use for online learning are bulky and inefficient (Gillis \& Krull, 2020; Jones, 2015; Kumar \& Owston, 2016; Lee et al., 2016) which can lead to their being used 
as places where information is simply disseminated, rather than genuine VLEs where the design and curriculum content can come together to connect students with each other for interaction and collaboration (Jones, 2015; Stone, 2019). Elementary schools, for instance, can be said to provide many opportunities for families to increase their informal social capital and high schools, colleges and universities often provide a student with guidance and counseling services not easily accessible elsewhere. In moving to online learning, these institutions must not forget their "organizational brokerage" (Domina et al., 2021, p. 4) in facilitating and maintaining these social connections lest their students suffer in isolation (Crea \& Sparnon, 2017). Ultimately, the VLE experience begins with the institution; if there is no commitment to ensuring the use of a high-quality LMS and no focus on securing and maintaining the human resource social supports that students and families have come to rely on the school to provide, then the mental health and academic achievement of its students can deteriorate (Cairns et al., 2020; Cavanaugh et al., 2004; Domina et al., 2021; Gillis \& Krull, 2020; Jones, 2015; Lee \& Oh, 2017; MerlinKnoblich et al., 2019; Rogowska et al., 2020; Stone, 2019; Xavier et al., 2020; Zhu \& van Winkel, 2016).

As Blayone et al. (2018) points out, vital to the VLE experience is "high quality activity design, strong environmental and motivational supports, and competent online facilitators" (p.15). Teacher readiness for both the technological scope of VLEs and for the new expectations that they are the sole social-emotional support for students and families (at the very least a proxy to such supports) is generally low. Training is essential for educators who are navigating new technologies and creating resources that provide meaningful opportunities for knowledge construction, reflection, and practice (Davies, 2014; Gibson \& Smith, 2018). Teachers must also be taught how to "adjust and find their own rhythm, providing sufficient presence while avoiding feeling perpetually 'on call"' (Jones, 2015, p. 227). Teachers lacked access to suitable training and felt ill-prepared to offer and provide to students with special needs or disabilities the appropriate accommodations within the VLE (Kent et al., 2018). Substantial professional development is needed to ensure that teachers know how to provide social opportunities in the VLE that encourages group work, formal and informal interactions, and peer-to-peer cooperative learning (Cavanaugh et al., 2004; Johnston et al., 2014; Zhu \& Van Winkel, 2016). Cultivating this socialemotional component is an essential task of the online educator; when a student can trust their teacher and their classmates, their self-efficacy and motivation increases and generally so does their performance and progress (Johnston et al., 2014). To accomplish this, institutions must increase their efforts in training and supporting their faculty to be ready for online instruction (Crea \& Sparnon, 2017).

Jena (2016) defines student learning readiness as "the body of skills needed by learners to learn" (p. 950). This body of skills and aptitudes includes, but is not limited to, motivation, self-regulation, perceived usefulness, confidence with using various technology, attitude, self-efficacy, computational abilities, communication skills, and research and critical thinking competence (Baker et al., 2019; Blayone et al., 2018; Du et al., 2019; Hursen, 2019; Johnston et al., 2014; Jones, 2015; Mallya et al., 2019). Beyond these attributes of learning readiness is also a strong necessity for a certain level of social-emotional maturity, most especially if the 
online learning was a result of the COVID-19 pandemic or of illness (i.e., not a free choice). Soft qualities such as resilience, flexibility, and positivity (Lee \& Oh, 2017) made it more possible for students to survive the transition from the routine and collaboration of a physical classroom to the more solitary and independent learning space of the VLE (Crea \& Sparnon, 2017; Gibson \& Smith, 2018; Jena, 2016). In addition to these crucial factors, is the technology-readiness of students. Students may not have access to their own personal device to do their schoolwork, and if they do, there is no guarantee that it is a device equipped with the sufficient technological specifications to handle the resource heavy online tools or that the student has access to high-speed internet to allow full and equal participation in the lesson and VLE (Domina et al., 2021; Gillis \& Krull, 2020; Hursen, 2019). It cannot be assumed that because students use technology at very high rates for personal relationships and entertainment that they can directly transfer those skills to the sophisticated and critical digital literacy necessary and conducive to learning in a VLE (Blayone et al., 2018; Roblek et al., 2019). Indeed, the various online tools that are familiar to institutions and educators are rarely in the purview of students, though when the need arises, students do want to be taught how to use the many programs and LMSs available to them effectively (Stone, 2019) and thus system readiness, student readiness, student inclusion, student achievement and teacher readiness are inseparable (Huang et al., 2011; Kumar \& Owston, 2016; Pryjmachuk et al., 2012; Yilmaz, 2019).

\subsection{The ideal VLE}

Among the reviewed articles, the answer to our second research question concerning the criteria of an ideal VLE emerged. VLEs which supported students both academically and emotionally and whereby online educators were engaged and motivated were highly organized and inventive, and if given that no barriers of readiness existed, could be implemented in every school system willing to pivot to this necessary focus. Firstly, policies and procedures that focus on the progress and socialemotional needs of the student must be in place (Archambault et al., 2013). This can only be achieved if a full set of human resources such as guidance teachers, attendance officers, counsellors and special education resource teachers are available both on a central campus and online (Johnston et al., 2014) offering "inclusion, communication, connection with others and proactive institutional support" (Stone, 2019, p. 7) by way of a school-home mentorship model (Barbour \& LaBonte, 2019). In this way, the student's isolation is lessened and, united with the educational team, the VLE teacher can focus on lending their subject and pedagogical expertise to their students (Driscoll et al., 2012; Du et al., 2019; Engelbertink et al., 2020; Wingo et al., 2016; Zhu \& van Winkel, 2016). Secondly, the VLE must be easy to use, accessible, flexible, and innovative. Institutions must select uncomplicated LMSs for teachers to use to deliver their program. The expectations of use must also be communicated to all faculty to ensure a seamless experience for students (Jones, 2015). As well, in either a synchronous VLE or BLM, having easy access to recorded lessons is crucial, especially for students with disabilities or who are still learning the language (Davies, 2014; Dommett et al., 2019; Kumar \& Owston, 2016). Investment 
in innovative tools and technologies is necessary to keep the VLE from becoming stagnant for students and, depending on the technology, can promote healthy, rich, and meaningful student interactions (Du et al., 2019). There is promising research in the use of tools such as AR, VR, 3DVR and 3DVE to create experiences and spaces that allow students to attend to one another virtually. These tools help to cultivate positive relationships, academic and personal confidence, and good mental health (Huang et al., 2019; Lan et al., 2018; Papanastasiou et al., 2019; Stone, 2019). Thirdly, there must be, at best, a live-video synchronous component to the VLE, or at minimum, the availability of synchronous office-hours (Stone, 2019; Wingo et al., 2016; Zeren, 2015; Zhu \& van Winkel, 2016). When students and teachers were engaged face-to-face, body language and tone could be better understood and relationship markers such as trust and care could be better perceived (Driscoll et al., 2012; Johnston et al., 2014; Wingo et al., 2016). Finally, the VLE must engage students in becoming digital citizens together. VLEs that provide opportunities for students to engage formally and informally enable students to increase their academic self-efficacy, increase their learning outcomes, and mitigate any mental health issues that may result from the perceived isolation of online learning (Driscoll et al., 2012; Du et al., 2019; Engelbertink et al., 2020; Johnston et al., 2014; Stone, 2019; Yilmaz, 2019; Zhu \& van Winkel, 2016).

\subsection{Discussion of gaps and limitations in the research and suggestions for further inquiry}

The attempt to study any observable intersection of VLE implementation and student mental health presents unique logistical and philosophical queries that remain unquelled. Such wonderings involve the state of how participant numbers are determined, the founding modalities in which self-reported qualitative data is obtained, the rationale, or lack thereof, of why specific LMS platforms were used in the existing studies, and the generally perceived evolving nature of VLEs. Taken together, the various streams of inadequate information fret deeply and, perhaps, create quite significant gaps. In the following discussion of these gaps, we will humbly aim to make moderate suggestions for further inquiry that could enrich the current available research.

Concerning the limitations in obtaining meaningful participation, a key area that remained challenging among the research was ensuring that participant profiles were not assembled out of simply convenient contexts of implementation. Indeed, quality research is exhorted to communicate, as narrowly as possible, the contexts in which they are situated. However, our search yielded a number of studies that were isolated case studies (e.g., Archambault et al., 2013; Johnston et al., 2014; Jones, 2015; Kumar \& Owston, 2016) or were relegated to being singularly quasi-experimental (e.g., Blayone et al., 2018; Davies, 2018; Driscoll et al., 2012; Ho et al., 2016; Huang et al., 2011; Lee et al., 2016) in nature due to the fact that their implementation was imposed upon pre-existing participant groupings - those who happened to be enrolled in the class that was chosen for intervention. In extension to this, adequate control conditions were not always apparent, especially those which 
considered many factors that were changed in the experience of intervention groups. That is all to say that the interventions themselves were multifaceted, and one could surmise a possible inability to distinguish which key facet or combination was pivotal in the intervention. This issue may be considered a specific function of the sheer complexity of studying VLE implementations themselves. It is further compounded in the noting of pre-existing intervention groupings as it is perhaps the result of simple pragmatism in observing VLE implementations where they are available to be observed. This point recognizes that VLEs require specific access to resources that may be limited, making widespread and universally approachable studies a challenge. Here, it is possible that an underlying dynamic exists in the research where actioning any opportunity for study, however limited, is better than conducting no study at all. In our view, further inquiry into VLE efficacy and its relation to the mental health of students, should endeavour to include randomized trials, whereby there is no observed previous relationship between the intervention group and the researcher.

Another limitation to this scoping review related to participant selection is the scale and size of many of the studies. Several studies combined the type of participant, blending the experiences of students, faculty, and education support staff, thus limiting a focus on the unique perspective of the student as the end-user (e.g., Crea \& Sparnon, 2017; Dommett et al., 2019; Engelbertink et al., 2020; Johnston et al., 2014; Stone, 2019; Wingo et al., 2016). Additionally, some studies that reported findings concerning students directly were of an extremely small student sample size of thirty or less (e.g., Cairns et al., 2020; Dommett et al., 2019; Engebertink et al., 2020; Hursen, 2019; Johnston et al., 2014; Kumar \& Owston, 2016; Lan et al., 2018; Wingo et al., 2016; Zeren, 2015; Zhu \& van Winkel, 2016). We note this small sample size in order to frame the perceived usefulness of these studies in the Ontario education context noting that Ontario Regulation 484/20, s. 4(14.1) states that "the average size in a school year of a board's online learning classes shall not exceed 30 ". It is our view that findings of studies with a less than thirty sample size should be interpreted cautiously, as the dynamics and pressures conspicuous in an average sized class cannot be accurately measured. For further inquiry, we would suggest research that included groups of whole divisions across multiple school boards allowing for parallel interpretation and consistency.

A further limitation of this scoping review is the lack of consistency in LMS research. In as many facets as teachers differ so too do the online VLE tools that may be utilized to deliver programming and the effects of each LMS's nuances can be difficult to account for and isolate as non-contributing factors within the studies. Several studies looked specifically at the Blackboard LMS (e.g., Crea \& Sparnon, 2017; Davies, 2014; Du et al., 2019; Engebertink et al., 2020; Kent et al., 2018; Lee et al., 2016; Pryjmachuk et al., 2012) noting that in most cases its use was pragmatically chosen as it was already in use by the hosting institution. As well, multiple studies looked at either outdated programs, such as Facebook and RSS feeds (e.g., Huang et al., 2011; Hursen, 2018; Yilmaz, 2019) or expensive and new technology, such as 3DVR and iPads (e.g., Davies, 2014; Huang et al., 2019; Lan et al., 2018), that would be quite financially out of reach for most Ontario school boards to implement in any widespread and equitable fashion. Overall, researchers instead focused 
on studying only the perceptions of online learning in general or one specific piece of the online learning experience (for instance, the posting of recorded lectures or an asynchronous discussion board section) without giving any precise attention to the LMS used to create the VLE. In fact, it can be seen that the largest gap in the research is ignoring the LMS as a true, unto itself environment. We find this to be crucial to our research focus of determining how the perceived humanity of the VLE affects the mental health of the student; after all, it is the space in which the student will be spending most of their learning hours.

Many of the studies relied upon qualitative data gathered via surveys during the intervention which required participants to self-report on their perceived well-being and mental health. This paradigm of understanding reads as akin to consumer-based research where one who is satisfied with a product is more likely to repeat consumption regardless of whether the product ultimately increases quality of life. Just as the terms pleasure and contentment are not interchangeable, in the context of the research, it remains unclear if a participant's self-reporting on perceived levels of anxiety is congruent with clinical definitions of the terms. While studies which utilized this form of data collection are free of equivocation by way of maintaining qualifying language such as "perceived level of anxiety" and not simply state "anxiety", the question of the results being meaningful still remains. A suggestion for further inquiry may entail the implementation of standardized data sources such as the PSS-10, the CES-D, and the MBI-SS utilized by Lee and Oh (2017). Caution must be employed when developing questionnaires, interview questions, and surveys that provide opportunities to participants for open-ended self-reporting.

A final point on the limits of VLE research rests in the concern that LMSs may evolve at rates that do not allow for consistent implementation and ample research to be conducted in a timely manner. In an earlier section of this scoping review, we referenced the lack of research as a product of the field being relatively novel in nature. However, for several years now, LMSs have offered functionalities that extend into the realm of real-time collaboration that is inclusive of visual presence with teachers as well as being fully capable of allowing students fluid peer-to-peer real-time engagement. In considering this it is astonishing that our research showed such a vast range in how VLE operated in relation to the available technology. This has led us to wonder if the technology is available, why is it not being utilized and studied in a way that reflects its full capabilities? Aside from the concepts of readiness that have been earlier itemized and discussed, the level of investment that an institution is willing to make of a platform and the rate of making that LMS available with a fully optioned suite, becomes the pivoting element. Further, if a gradual investment model is employed, where not all features of the LMS are available at the onset, each time a new feature is doled out, it becomes a potential point of relearning and creates inefficiencies if there are not ample professional development opportunities for educators.

While determining our final research terms for this scoping review, we had initially searched for studies that were exclusively for the K-12 sphere and unsuspectingly this did not prove to be fruitful. We noted earlier that a peculiar number of studies had been published using nursing students as the study participants, reporting on their role as student and practitioner. We believe that the near exclusivity 
of undergraduate students in the research limited our ability to present a complete picture of the current state of VLEs for all students. In The Human Face of Mental Health and Mental Illness in Canada, the Government of Canada (2006) reported that "two-thirds (68.8\%) of young adults aged 15-24 years with a mood or anxiety disorder reported that their symptoms had started before the age of 15" (p. 34). Boak et al. (2016) support these conclusions, showing in their report that "one-third (34\%) of students indicate a moderate-to-serious level of psychological distress (symptoms of anxiety and depression)" (p. iv) and "one-in-eight (12\%) students had serious thoughts about suicide in the past year" (p. iv), a statistic that has remained consistent over the past fifteen years of reporting. Given these unsettling statistics, we would have thought that the rich and varied K-12 arena would have been a sphere where there would be a surfeit of mental health research related to VLE utilization. Instead, our search results yielded studies that disproportionately represented participant groups outside of our desired range of inquiry; just six included the experiences of K-12 students, and in each of those studies, the students' caregivers were the primary data source. K-12 students often spend more than half their waking hours in school environments and VLEs; it is notably unclear why most of the studies observed in this scoping review are unilaterally disinterested in exploring an identified area of need for mental health support. We believe it would be prudent to prioritize research on the mental health of K-12 students engaged in VLEs which Domina et al. (2021) has shown can be isolating, psychologically disruptive, and exhausting experiences.

\section{Suggestions for educator practice}

Though there is variety in the identified gaps detailed above, our research maintained a consistent thread that related to the criteria of the ideal VLE for both the success of the educator but also the well-being and dignity of the student. From this work, we endeavour to make a few moderate suggestions for online educators:

- Where possible and where privacy concerns can be mitigated, conduct lessons and office hours using live videoconferencing. Whether the VLE is a secondary component in a BLM arrangement, or it is the primary mode of program delivery, maintaining a personal face-to-face connection is an essential component to a student's feelings of connectedness and motivation.

- Avoid viewing the VLE as merely a space to bank work packages and collect evaluations. Rather, aim to create a space where both formal and informal interactions can occur, synchronously and asynchronously. Many LMSs have the capability to incorporate a variety of third-party online teaching and learning tools to aid educators in creating a multi-modal experience for students.

- Be vulnerable and take advantage of learning opportunities when they become available. It takes an enormous amount of energy and resources to run stimulating programs that speak honestly to curriculum content, allow for individual learning needs, and that are cognizant to the social-emotional well-being of students. The responsibilities and conditions of an online educator are well-primed 
for strain; be mindful of the added pressure and allow the professional development that is available to inform practice but not make hurried demands of that practice.

\section{Conclusion}

If educational research involves an ethical component, it would be incumbent on institutions to see that research reflects areas of need within communities. It is our hope that this scoping review might provide modest insight into the current state of research that concerns student mental health in VLE contexts, while casting light on the need for new research initiatives to be undertaken in the K-12 sphere. As it stands, there lies the strong possibility that K-12 students are experiencing VLE implementations that do not actively partake in the qualities of a VLE that soundly offer best practices, working to support the mental health needs of students. To build strong VLE's for K-12 students, research campaigns ought to offer architectures that are universalized in their implementation and fundamentally repeatable. This requires a commitment beyond that of the researchers involved, but also a willingness of the institutions who serve the participants of such a sweeping study to abide by the research. Without such research, institutions which utilize VLEs can only continue on sometimes arbitrary perceptions of how best to serve student wellness. Persisting in the status quo as such leaves students vulnerable to practices that might institutionally under-serve them and have potential generational implications. Interestingly, one might argue that, without such research, institutions who offer VLEs might garner the ability to omit themselves of the direct responsibility to provide those qualities of VLEs that would be found to support mental health and exclude those qualities that are found to diminish mental health.

As a closing thought and to return to the experiential modus and inquiry of this review, we adjure future research to be guided by the question of how the student encounters their teacher within the VLE. Emmanuel Levinas, a philosopher who wrote extensively on the innate ethical experience that is garnered through face-toface interaction, took a rare moment in his writing to offer insight on the dynamics of education. In Levinas' Totality and Infinity, he notes that in being called to respond to the Other, "[teaching] designates an interior being that is capable of a relation with the exterior and does not take its own interiority for the totality of being" (Levinas, 1969, as cited in Zhao, 2016, p. 324). Here, Levinas may appear to point to the disposition of the educator as one that offers the presence of self for the sake of the students' being. This sentiment, taken along with the intriguing metaanalysis offered by Mesman et al. (2009) may do little to establish the "how" of education as conveyed through this inquiry, but certainly makes a tremendous stride in the realm of the "why" that institutions ought to work to expound among the current VLE modalities that they are imposing upon learning communities.

Acknowledgements The authors would like to thank Dr. Christopher Gilham for his comments and guidance on a previous version of this manuscript.

Data availability Not Applicable. 
Code availability Not Applicable.

\section{Declarations}

Conflicts of interest/Competing interests Not applicable.

Open Access This article is licensed under a Creative Commons Attribution 4.0 International License, which permits use, sharing, adaptation, distribution and reproduction in any medium or format, as long as you give appropriate credit to the original author(s) and the source, provide a link to the Creative Commons licence, and indicate if changes were made. The images or other third party material in this article are included in the article's Creative Commons licence, unless indicated otherwise in a credit line to the material. If material is not included in the article's Creative Commons licence and your intended use is not permitted by statutory regulation or exceeds the permitted use, you will need to obtain permission directly from the copyright holder. To view a copy of this licence, visit http://creativecommons.org/licen ses/by/4.0/.

\section{References}

Al Karani, A., \& Thobaity, A. (2020). Medical staff members' experiences with Blackboard at Taif University, Saudi Arabia. Journal of Multidisciplinary Healthcare, 2020(13), 1629-1634. https://doi. org/10.2147/JMDH.S287389

Anderson, S., Allen, P., Peckham, S., \& Goodwin, N. (2008). Asking the right questions: Scoping studies in the commissioning of research on the organisation and delivery of health services. Health Research and Policy Systems, 6(7), 1-12. https://doi.org/10.1186/1478-4505-6-7

Archambault, L., Kennedy, K., \& Bender, S. (2013). Cyber-truancy: Addressing issues of attendance in the digital age. Journal of Research on Technology in Education, 46(1), 1-28. http://libproxy.stfx.ca/ login?url=https://www-proquest-com.libproxy.stfx.ca/scholarly-journals/cyber-truancy-addressingissues-attendance/docview/1492734861/se-2?accountid=13803. Accessed 9 Feb 2021.

Ault, M. J., Courtrade, G., Miracle, S. A., \& Bruce, A. E. (2020). Providing support for rural special educators during nontraditional instruction: One state's response. Rural Special Education Quarterly, 39(4), 193-200. https://doi.org/10.1177/8756870520959653

Baker, R., Evans, B., Li, Q., \& Cung, B. (2019). Does inducing students to schedule lecture watching in online classes improve their academic performance? An experimental analysis of a time management intervention. Research in Higher Education, 60(4), 521-552. https://doi.org/10.1007/ s11162-018-9521-3

Barbour, M.K., \& Labonte, R. (2019). Sense of irony or perfect timing: Examining the research supporting proposed e-learning changes in Ontario. International Journal of E-Learning \& Distance Education, 34(2), 1-30. http://libproxy.stfx.ca/login?url=https://www-proquest-com.libproxy.stfx.ca/ scholarly-journals/sense-irony-perfect-timing-examining-research/docview/2350114007/se-2?accou ntid=13803. Accessed 9 Feb 2021.

Blayone, T. J. B., Mykhailenko, O., Kavtaradze, M., Kokhan, M., van Oostveen, R., \& Barber, W. (2018). Profiling the digital readiness of higher education students for transformative online learning in the post-soviet nations of Georgia and Ukraine. International Journal of Educational Technology in Higher Education, 15, 1-22. https://doi.org/10.1186/s41239-018-0119-9

Boak, A., Hamilton, H., Adlaf, E., Henderson, J., \& Mann, R. (2016). The mental health and well-being of Ontario students, 1991-2015: Detailed OSDUHS findings. CAMH Research Document Series no. 43. Toronto: Centre for Addiction and Mental Health.

Cairns, M.R., Ebinger, M., Stinson, C., \& Jordan, J. (2020). COVID-19 and human connection: Collaborative research on loneliness and online worlds from a socially-distanced academy. Human Organization, 79(4), 281-291. https://www-proquest-com.libproxy.stfx.ca/docview/2472333748/fulltextPDF/84C6807DFE224A65PQ/1?accountid=13803. Accessed 9 Feb 2021. 
Cavanaugh, C., Gillian, K.J., Kromrey, J., Hess, M., \& Blomeyer, R. (2004) The effects of distance education on K-12 student outcomes: A meta-analysis. Learning Point Associates. https://eric.ed.gov/?id= ED489533. Accessed 9 Feb 2021.

Chugani, C., \& Houtrow, A. (2020). Effect of the COVID-19 pandemic on college students with disabilities. American Journal of Public Health, 110(12), 1722-1723. https://doi.org/10.2105/AJPH.2020. 305983

Crea, T. M., \& Sparnon, N. (2017). Democratizing education at the margins: Faculty and practitioner perspectives on delivering online tertiary education for refugees. International Journal of Educational Technology in Higher Education, 14, 1-19. https://doi.org/10.1186/s41239-017-0081-y

Davies, M. (2014). Using the Apple iPad to facilitate student-led group work and seminar presentation. Nurse Education in Practice, 14(4), 363-367. https://doi.org/10.1016/j.nepr.2014.01.006

Domina, T., Renzulli, L., Murray, B., Garza, A.N. \& Perez, L. (2021). Remote or removed: Predicting successful engagement with online learning during COVID-19. Socius: Sociological Research for a Dynamic World, 7, 1-15. https://doi.org/10.1177/2378023120988200

Dommett, E. J., Gardner, B., \& van Tilburg, W. (2019). Staff and student views of lecture capture: A qualitative study. International Journal of Educational Technology in Higher Education, 16(23), 1-12. https://doi.org/10.1186/s41239-019-0153-2

Driscoll, A., Jicha, K., Hunt, A. N., Tichavsky, L., \& Thompson, G. (2012). Can online courses deliver in-class results?: A comparison of student performance and satisfaction in an online versus a faceto-face introductory sociology course. Teaching Sociology, 40(4), 312-331. https://doi.org/10.1177/ $0092055 X 12446624$

Du, J., Fan, X., Xu, J., Wang, C., Sun, L., \& Liu, F. (2019). Predictors for students' self-efficacy in online collaborative groupwork. Educational Technology Research and Development, 67, 767-791. https:// doi.org/10.1007/s11423-018-9631-9

Engelbertink, M. M. J., Kelders, S. M., Woudt-Mittendorff, K. M., \& Westerhof, G. J. (2020). Participatory design of persuasive technology in a blended learning course: A qualitative study. Education and Information Technologies, 25(5), 4115-4138. https://doi.org/10.1007/s10639-020-10147-X

Gardner, M. (2020). Lecture captures adds value to attending psychological research methods lectures. Scholarship of Teaching and Learning in Psychology. Advance online publication. http://dx.doi. org/https://doi.org/10.1037/st10000212

Gibson, P. F., \& Smith, S. (2018). Digital literacies: Preparing pupils and students for their information journey in the twenty-first century. Journal of Information and Learning Science, 119(12), 733-742. https://doi.org/10.1108/ILS-07-2018-0059

Gillis, A., \& Krull, L. M. (2020). COVID-19 remote learning transition in spring 2020: Class structures, student perceptions, and inequality in college courses. Teaching Sociology, 48(4), 283-299. https:// doi.org/10.1177/0092055X20954263

Government of Canada. (2006). The human face of mental health and mental illness in Canada. https:// www.phac-aspc.gc.ca/publicat/human-humain06/pdf/human_face_e.pdf. Accessed 9 Feb 2021.

Ho, V.-T., Nakamori, Y., Ho, T.-B., \& Ping Lim, C. (2016). Blended learning model on hands-on approach for in-service secondary school teachers: Combination of e-learning and face-to-face discussion. Education and Information Technologies, 21(1), 185-208. https://doi.org/10.1007/ s10639-014-9315-y

The Hospital for Sick Children. (2021, January 21). COVID-19: Guidance for school operation during the pandemic. https://www.sickkids.ca/siteassets/news/news-archive/2021/covid19-guidance-forschool-operation-sickkids.pdf. Accessed 9 Feb 2021.

Huang, T.-C., Huang, Y.-M., \& Yu, F.-Y. (2011). Cooperative weblog learning in higher education: Its facilitating effects on social interaction, time lag, and cognitive load. Journal of Educational Technology \& Society, 14(1), 95-106. http://libproxy.stfx.ca/login?url=https://www-proquest-com.libpr oxy.stfx.ca/scholarly-journals/cooperative-weblog-learning-higher-education/docview/1287031679/ se-2?accountid=13803. Accessed 9 Feb 2021.

Huang, Y., Backman, S. J., Backman, K. F., McGuire, F. A., \& DeWayne, M. (2019). An investigation of motivation and experience in virtual learning environments: A self-determination theory. Education and Information Technologies, 24(1), 591-611. https://doi.org/10.1007/s10639-018-9784-5

Hursen, C. (2019). The effect of technology supported problem-based learning approach on adults' selfefficacy perception for research-inquiry. Education and Information Technologies, 24(2), 13602357. https://doi.org/10.1007/s10639-018-9822-3 
Jena, R. K. (2016). Investigating the interrelation between attitudes, learning readiness, and learning styles under virtual learning environment: A study among Indian students. Behavior and Information Technology, 35(11), 946-957. https://doi.org/10.1080/0144929X.2016.1212930

Johnston, S.C., Greer, D., \& Smith, S.J. (2014). Peer learning in virtual schools. Journal of Distance Education, 28(1), 1-31. http://www.ijede.ca/index.php/jde/article/view/853. Accessed 9 Feb 2021.

Jones, S. (2015). Benefits and challenges of online education for clinical social work: Three examples. Clinical Social Work Journal, 43(2), 225-235. https://doi.org/10.1007/s10615-014-0508-z

Kent, M., Ellis, K., \& Giles, M. (2018). Students with disabilities and eLearning in Australia: Experiences of accessibility and disclosure at Curtin University. TechTrends, 62(6), 654-663. 10-1007/ s11528-018-0337-y

Kumar, K. L., \& Owston, R. (2016). Evaluating e-learning accessibility by automated and student-centered methods. Educational Technology, Research and Development, 64(2), 263-283. https://doi. org/10.1007/s11423-015-9413-6

Lan, Y.-J., Hsiao, I.Y.T., \& Shih, M.-F. (2018). Effective learning design of game-based 3D virtual language learning environments for special education students. Journal of Educational Technology \& Society, 21(3), 213-227. https://www-proquestcom.libproxy.stfx.ca/docview/2147865547?accou ntid=13803. Accessed 9 Feb 2021.

Lee, S. J., Ngampornchai, A., Trail-Constant, T., Abril, A., \& Srinivasan, S. (2016). Does a case-based online group project increase students' satisfaction with interaction in online courses? Active Learning in Higher Education, 17(3), 249-260. https://doi.org/10.1177/1469787416654800

Lee, S.M., \& Oh., Y. (2017). The mediator role of perceived stress in the relationship between academic stress and depressive symptoms among e-learning students with visual impairments. Journal of Visual Impairment \& Blindness, 111(2), 123-127. https://files.eric.ed.gov/fulltext/EJ1137410.pdf [accessed 9 February 2021].

Mallya, J., Lakshminarayanan, S., \& Payini, V. (2019). Self-efficacy as an antecedent to students' behavioral intention to use the internet for academic purposes: A structural equation modelling approach. Library Philosophy and Practice, 1-12. http://libproxy.stfx.ca/login?url=https://www-proquestcom.libproxy.stfx.ca/scholarly-journals/self-efficacy-as-antecedent-students-behavioral/docview/ 2299764012/se-2?accountid=13803. Accessed 9 Feb 2021.

Manthey, L., Vehreschild, V., \& Renner, K.-H. (2016). Effectiveness of two cognitive interventions promoting happiness with video-based online instructions. Journal of Happiness Studies, 17(1), 319339. https://doi.org/10.1007/s10902-014-9596-2

Means, B., Toyama, Y., Murphy, R., Bakia, M., \& Jones, K. U.S. Department of Education. (2009). Evaluation of evidence-based practices in online learning: A meta-analysis and review of online learning studies. https://www2.ed.gov/rschstat/eval/tech/evidence-based-practices/finalreport.pdf. Accessed 9 Feb 2021.

Merlin-Knoblich, C., Harris, P.N., \& Mason, E.C.M. (2019). Examining student classroom engagement in flipped and non-flipped counsellor education courses. The Professional Counselor, 9(2), 109125. https://doi.org/10.15241/cmk.9.2.109

Mesman, J., van Ijzendoorn, M., \& Bakermans-Kranenburg, M. (2009). The many faces of the still-face paradigm: A review and meta-analysis. Developmental Review, 29(2), 120-162. https://doi.org/10. 1016/j.dr.2009.02.001

Miller, J. (2020, April). Learning from home won't drag down grades for high school students, promises Ottawa board. Ottawa Citizen, https://ottawacitizen.com/news/local-news/learning-from-homewont-drag-down-grades-for-high-school-students-promises-ottawa-board. Accessed 9 Feb 2021.

Ontario College of Teachers. (2020). Ethical Standards. https://www.oct.ca/public/professional-stand ards/ethical-standards

Ontario Education Act (1990) O Reg. 484/20, s. 4(14.1). Retrieved from Ontario e-Laws website: https:// www.ontario.ca/laws/regulation/120132

Ontario Education Act, R.S.O. 1990, c. E.2. Retrieved from Ontario e-Laws website: https://www.ontar io.ca/laws/statute/90e02\#BK441

OECTA. (May 11, 2020). Statement from OECTA president Liz Stuart on "Synchronous Learning”. https://www.catholicteachers.ca/News-Events/News/Releases/Statement-from-OECTA-Presi dent-Liz-Stuart-on-the-M. Accessed 9 Feb 2021.

Ontario Ministry of Education. (2020). Policy/Program Memorandum No. 164. http://www.edu.gov.on. ca/extra/eng/ppm/164.html. Accessed 9 Feb 2021. 
Papanastasiou, G., Drigas, A., Skianis, C., Lytras, M., \& Papanastasiou, E. (2019). Virtual and augmented reality effects on K-12, higher and tertiary education students' twenty-first century skills. Virtual Reality, 23(4), 425-436. https://doi.org/10.1007/s10055-018-0363-2

Pryjmachuk, S., Gill, A., Wood, P., Olleveant, N., \& Keeley, P. (2012). Evaluation of an online study skills course. Active Learning in Higher Education, 13(2), 155-168. https://doi.org/10.1177/14697 87412441298

Roblek, V., Mesko, M., Dimovski, V., \& Peterlin, J. (2019). Smart technologies as social innovation and complex social issues of the $\mathrm{Z}$ generation. Kybernetes, 48(1), 91-107. https://doi.org/10. 1108/K-09-2017-0356

Rogowska, A. M., Kuśnierz, C., \& Bokszczanin, A. (2020). Examining anxiety, life satisfaction, general health, stress and coping styles during COVID-19 pandemic in Polish sample of university students. Psychology Research and Behavior Management, 13, 797-811. https://doi.org/10.2147/PRBM. S266511

Rowe, D. A., Carter, E., Gajjar, S., Maves, E. A., \& Wall, J. C. (2020). Supporting strong transitions remotely: Considerations and complexities for rural communities during COVID-19. Rural Special Education Quarterly, 39(4), 220-232. https://doi.org/10.1177/8756870520958199

Schlesselman, L. (2020). Perspective from a teaching and learning center during emergency remote teaching. American Journal of Pharmaceutical Education, 84(8), 1042-1044. https://doi.org/10. 5688/ajpe 8142

Shawaqfeh, M., Al Bekairy, A., Al-Azayzih, A., Alkatheri, A., Qandil, A., Obaidat, A., Al Harbi, S., \& Muflih, S. (2020). Pharmacy students perceptions of their distance online learning experience during the COVID-19 pandemic: A cross-sectional survey study. Journal of Medical Education and Curricular Development, 7, 1-9. https://doi.org/10.1177/2382120520963039

Shea, K. L., \& Rovera, E. J. (2021). Preparing for the COVID-19 pandemic and its impact on a nursing simulation curriculum. Journal of Nursing Education, 60(1), 52-55. https://doi.org/10.3928/01484 834-20201217-12

Stone, C. (2019). Online learning in Australian higher education: Opportunities, challenges and transformations. Student Success, 10(2), 1-11. https://doi.org/10.5204/ssj.v10i2.1299

Toulouse, C. (2020). Screen capture recordings enhance connectedness among students, course content, and faculty. Journal of Nursing Education, 59(9), 531-535. https://doi.org/10.3928/0148483420200817-11

Tronick, E., Als, H., Adamson, L., Wise, S., \& Brazelton, E. (1978). The infant's response to entrapment between contradictory messages in face-to-face interaction. Journal of the American Academy of Child Psychiatry, 17(1), 1-13. https://doi.org/10.1016/S0002-7138(09)62273-1

Watermeyer, R., Crick, T., Knight, C., \& Goodall, J. (2021). COVID-19 and digital disruption in UK universities: Afflictions and affordances of emergency online migration. Higher Education, 81(3), 623-641. https://doi.org/10.1007/s10734-020-00561-y

Wingo, N. P., Peters, G. B., Ivankova, N. V., \& Gurley, D. K. (2016). Benefits and challenges of teaching nursing online: Exploring perspectives of different stakeholders. Journal of Nursing Education, 55(8), 433-440. https://doi.org/10.3928/01484834-20160715-03

Xavier, B., Camarneiro, A.P., Loureiro, L., Menino, E., Cunha-Oliveira, A., \& Monteiro, A.P. (2020). Impact of COVID-19 on the family, social, and academic dynamics of nursing students in Portugal. Revista de Enfemagem Referência, 5(4), 1-10. https://doi.org/10.12707/RV20104

Yilmaz, F. K. G. (2019). Exploring the role of Facebook adoption and virtual environment loneliness on knowledge sharing behaviors in a Facebook learning community. Education and Information Technologies, 24(5), 1699-1714. https://doi.org/10.1007/s10639-018-09854-3

Zeren, S.G. (2015). Face-to-face and online counselling: Client problems and satisfaction. Education and Science, 40(182), 127-141. https://doi.org/10.15390/EB.2015.4696

Zhao, G. (2016). Levinas and the philosophy of education. Educational Philosophy and Theory, 48(4), 323-330. https://doi.org/10.1080/00131857.2015.1041007

Zhu, C., \& van Winkel, L. (2016). A virtual learning environment for the continuation of education and its relationship with the mental well-being of chronically ill adolescents. Educational Psychology, 36(8), 1429-1442. https://doi.org/10.1080/01443410.2014.992393

Publisher's note Springer Nature remains neutral with regard to jurisdictional claims in published maps and institutional affiliations. 